Check for updates

Cite this: RSC Adv., 2017, 7, 52283

Received 19th October 2017

Accepted 3rd November 2017

DOI: 10.1039/c7ra11562h

rsc.li/rsc-advances

\section{Molecular simulations of MOF membranes for separation of ethane/ethene and ethane/methane mixtures $\uparrow$}

\begin{abstract}
Cigdem Altintas and Seda Keskin (iD *
Metal organic framework (MOF) membranes have been widely investigated for gas separation applications. Several MOFs have been recently examined for selective separation of $\mathrm{C}_{2} \mathrm{H}_{6}$. Considering the large number of available MOFs, it is not possible to fabricate and test the $\mathrm{C}_{2} \mathrm{H}_{6}$ separation performance of every single MOF membrane using purely experimental methods. In this study, we used molecular simulations to assess the membrane-based $\mathrm{C}_{2} \mathrm{H}_{6} / \mathrm{C}_{2} \mathrm{H}_{4}$ and $\mathrm{C}_{2} \mathrm{H}_{6} / \mathrm{CH}_{4}$ separation performances of 175 different MOF structures. This is the largest number of MOF membranes studied to date for $\mathrm{C}_{2} \mathrm{H}_{6}$ separation. We computed adsorption selectivity, diffusion selectivity, membrane selectivity and gas permeability of MOFs for $\mathrm{C}_{2} \mathrm{H}_{6} / \mathrm{C}_{2} \mathrm{H}_{4}$ and $\mathrm{C}_{2} \mathrm{H}_{6} / \mathrm{CH}_{4}$ mixtures. Our results show that a significant number of MOF membranes are $\mathrm{C}_{2} \mathrm{H}_{6}$ selective for $\mathrm{C}_{2} \mathrm{H}_{6} / \mathrm{C}_{2} \mathrm{H}_{4}$ separation in contrast to traditional nanoporous materials. Selectivity and permeability of MOF membranes were compared with other membrane materials, such as polymers, zeolites, and carbon molecular sieves. Several MOFs were identified to exceed the upper bound established for polymeric membranes and many MOF membranes exhibited higher gas permeabilities than zeolites and carbon molecular sieves. Examining the structure-performance relations of MOF membranes revealed that MOFs with cavity diameters between 6 and $9 \AA$, porosities lower than 0.50 , and surface areas between $500-1000 \mathrm{~m}^{2} \mathrm{~g}^{-1}$ have high $\mathrm{C}_{2} \mathrm{H}_{6}$ selectivities. The results of this study will be useful to guide the experiments to the most promising MOF membranes for efficient separation of $\mathrm{C}_{2} \mathrm{H}_{6}$ and to accelerate the development of new MOFs with high $\mathrm{C}_{2} \mathrm{H}_{6}$ selectivities.
\end{abstract}

\section{Introduction}

The separation of different members of the $\mathrm{C}_{2}$ hydrocarbon family has industrial importance because these molecules are primary feedstocks for various chemicals. ${ }^{1}$ Ethane/ethene $\left(\mathrm{C}_{2} \mathrm{H}_{6} / \mathrm{C}_{2} \mathrm{H}_{4}\right)$ separation is generally carried out using distillation. This is one of the most energy intensive single distillations practiced commercially. Separation of $\mathrm{C}_{2} \mathrm{H}_{6}$ from methane $\left(\mathrm{CH}_{4}\right)$ similarly requires energy intensive distillation operations. The energy and equipment costs associated with these gas separations could be significantly reduced by the development of alternative separation methods. ${ }^{2}$ Adsorption-based and membrane-based gas separations provide very large reductions in the energy consumption and costs of these processes. The greatest limitation in the applications of adsorption and membrane-based gas separation technologies is the low selectivity of the materials used as adsorbents and membranes. Research on identification of new materials that can achieve

Department of Chemical and Biological Engineering, Koc University, Rumelifeneri Yolu, Sariyer, 34450, Istanbul, Turkey. E-mail: skeskin@ku.edu.tr

$\dagger$ Electronic supplementary information (ESI) available: List of the MOFs studied in this work and their structural properties. Potential parameters of gas molecules used in the simulations. See DOI: $10.1039 / \mathrm{c} 7 \mathrm{ra} 11562 \mathrm{~h}$
$\mathrm{C}_{2} \mathrm{H}_{6}$ separations with high selectivity has gained significant attention in the last decade.

Metal organic frameworks (MOFs) are considered as a new class of nanoporous materials that can be used as adsorbents and membranes in various gas separations. MOFs are composed of metal ions connected with organic ligands. ${ }^{3}$ They have well-defined pore structures, ${ }^{4}$ large surface areas (500$\left.6500 \mathrm{~m}^{2} \mathrm{~g}^{-1}\right),{ }^{5}$ high porosities, good thermal and mechanical stabilities which make them strong candidates for gas separation applications. ${ }^{6,7}$ MOFs have been widely studied for adsorption of $\mathrm{CO}_{2}, \mathrm{CH}_{4}$, and $\mathrm{H}_{2}$ in addition to the separation of several gas mixtures including $\mathrm{CO}_{2} / \mathrm{CH}_{4}, \mathrm{CH}_{4} / \mathrm{H}_{2}, \mathrm{CO}_{2} / \mathrm{N}_{2}, \mathrm{CO}_{2} /$ $\mathrm{H}_{2}$ and noble gases. ${ }^{8-12}$ Most of the studies related to the gas separation with MOFs in the literature focused on the $\mathrm{CO}_{2}$ capture whereas research on $\mathrm{C}_{2} \mathrm{H}_{6}$ separation using MOFs has recently started. Several experimental studies measured singlecomponent adsorption isotherms of $\mathrm{CH}_{4}, \mathrm{C}_{2} \mathrm{H}_{4}$, and $\mathrm{C}_{2} \mathrm{H}_{6}$ in various MOFs and these initial studies showed that MOFs can be promising materials for $\mathrm{C}_{2} \mathrm{H}_{6}$ separations. ${ }^{13-23}$

Considering the large number of available MOFs, it is not practical to identify the most promising adsorbent materials using purely experimental manners. Most of the works used molecular simulations to study MOFs for adsorption-based $\mathrm{C}_{2} \mathrm{H}_{6}$ separations. Guo et al. used molecular simulations to 
study $\mathrm{C}_{2} \mathrm{H}_{6} / \mathrm{CH}_{4}$ separation in IRMOF-1 (isoreticular metal organic framework) and four different zeolitic imidazolate frameworks, ZIFs (ZIF-8, ZIF-71, ZIF-80, ZIF-90). ${ }^{24}$ They showed that ZIFs exhibit better $\mathrm{C}_{2} \mathrm{H}_{6} / \mathrm{CH}_{4}$ separation performance compared to MOR zeolite and IRMOF-1. Wu et al. studied four different ZIFs using molecular simulations and reported their $\mathrm{C}_{2} \mathrm{H}_{6} / \mathrm{C}_{2} \mathrm{H}_{4}$ selectivities. ${ }^{25}$ Pillai et al. carried out molecular simulations to explore $\mathrm{C}_{2} \mathrm{H}_{6} / \mathrm{C}_{2} \mathrm{H}_{4}$ separation in interpenetrated and non-interpenetrated IRMOF-8 and reported $\mathrm{C}_{2} \mathrm{H}_{6}$ selectivities. ${ }^{26}$ We recently performed the first large-scale molecular simulation study for $\mathrm{C}_{2} \mathrm{H}_{6} / \mathrm{C}_{2} \mathrm{H}_{4}$ and $\mathrm{C}_{2} \mathrm{H}_{6} / \mathrm{CH}_{4}$ separations using MOFs and reported adsorption selectivity of 278 different MOFs. ${ }^{27}$ Our results showed that there is a large number of MOFs that exhibit significantly higher adsorption selectivity than zeolites for separation of $\mathrm{C}_{2} \mathrm{H}_{6} / \mathrm{C}_{2} \mathrm{H}_{4}$ and $\mathrm{C}_{2} \mathrm{H}_{6} / \mathrm{CH}_{4}$ mixtures. All these studies suggest that $\mathrm{MOFs}$ have strong potential to be used in adsorption-based $\mathrm{C}_{2} \mathrm{H}_{6} / \mathrm{C}_{2} \mathrm{H}_{4}$ and $\mathrm{C}_{2} \mathrm{H}_{6}$ / $\mathrm{CH}_{4}$ separations.

Membrane-based $\mathrm{C}_{2} \mathrm{H}_{6}$ separation is an alternative to the adsorption-based separation. Conventional polymeric membranes cannot achieve the desired performance, combination of high selectivity and high permeability, required for $\mathrm{C}_{2} \mathrm{H}_{6}$ separation. ${ }^{28-31}$ Polymers with high selectivity exhibit low permeability and polymers that have high gas permeability suffer from low selectivity. Due to this trade-off, recent studies have been directed towards developing more advanced membrane materials for $\mathrm{C}_{2} \mathrm{H}_{6}$ separations. Identification of MOF membranes that can achieve both high selectivity and high permeability will be very useful to replace polymeric membranes with MOFs. However, we have very limited information about the membrane-based $\mathrm{C}_{2} \mathrm{H}_{6}$ separation potential of MOFs. The number of studies focusing on $\mathrm{C}_{2} \mathrm{H}_{6} / \mathrm{C}_{2} \mathrm{H}_{4}$ and $\mathrm{C}_{2} \mathrm{H}_{6} / \mathrm{CH}_{4}$ separations with MOF membranes is scarce in the literature. Only two different types of MOFs were used as membranes for $\mathrm{C}_{2} \mathrm{H}_{6} / \mathrm{C}_{2} \mathrm{H}_{4}$ separation. Bux et al. predicted membrane selectivity of ZIF-8 as the product of adsorption and diffusion selectivities for an equimolar $\mathrm{C}_{2} \mathrm{H}_{6} / \mathrm{C}_{2} \mathrm{H}_{4}$ mixture. ${ }^{15}$ They reported that $\mathrm{C}_{2} \mathrm{H}_{6}$ adsorbs stronger than $\mathrm{C}_{2} \mathrm{H}_{4}$ but $\mathrm{C}_{2} \mathrm{H}_{4}$ diffuses faster and overcompensates the adsorption preference for $\mathrm{C}_{2} \mathrm{H}_{6}$, resulting in a MOF membrane that is weakly selective for $\mathrm{C}_{2} \mathrm{H}_{4}$. Pan and Lai reported single-component permeances of $\mathrm{CH}_{4}, \mathrm{C}_{2} \mathrm{H}_{4}$ and $\mathrm{C}_{2} \mathrm{H}_{6}$ through ZIF- 8 membranes. ${ }^{32}$ Caro's group reported single-component permeances of $\mathrm{CH}_{4}$ and $\mathrm{C}_{2} \mathrm{H}_{6}$ for ZIF-90 membranes. ${ }^{33}$ MOFs were recently used as filler particles in polymers to fabricate mixed matrix membranes (MMMs) in order to improve $\mathrm{C}_{2} \mathrm{H}_{6}$ and $\mathrm{C}_{2} \mathrm{H}_{4}$ permeabilities of polymers. ${ }^{34-37}$

Predicting separation performances of MOF membranes requires diffusion coefficients of $\mathrm{C}_{2} \mathrm{H}_{6} / \mathrm{C}_{2} \mathrm{H}_{4}$ and $\mathrm{C}_{2} \mathrm{H}_{6} / \mathrm{CH}_{4}$ mixtures through the pores of MOFs. Stallmach et al. reported intra-crystalline self-diffusion of $\mathrm{CH}_{4}$ and $\mathrm{C}_{2} \mathrm{H}_{6}$ in MOF-5 (also known as IRMOF-1) using pulsed field gradient (PFG) NMR technique. ${ }^{38}$ Ford et al. reported self-diffusivity of $\mathrm{CH}_{4}$ and $\mathrm{C}_{2} \mathrm{H}_{6}$ in MOF-5 using experiments and molecular simulations. ${ }^{39}$ Chmelik et al. studied diffusion of $\mathrm{C}_{2} \mathrm{H}_{6} / \mathrm{C}_{2} \mathrm{H}_{4}$ mixtures in ZIF-8 using different NMR techniques and showed that $\mathrm{C}_{2} \mathrm{H}_{4}$ diffusion is 5 times faster than $\mathrm{C}_{2} \mathrm{H}_{6}$ diffusion. ${ }^{40}$ Molecular simulations were used to compute self-diffusivity of $\mathrm{CH}_{4}$ in MOF-5.9,41,42 Borah et al. recently conducted molecular dynamics simulations to predict diffusion behavior of pure $\mathrm{CH}_{4}$ and $\mathrm{C}_{2} \mathrm{H}_{6}$ in 6 different MOFs. ${ }^{43}$ Self-diffusivities of $\mathrm{C}_{2} \mathrm{H}_{6},{ }^{44}$ $\mathrm{C}_{2} \mathrm{H}_{4},{ }^{45}$ and transport diffusivities of $\mathrm{CH}_{4}, \mathrm{C}_{2} \mathrm{H}_{4}$, and $\mathrm{C}_{2} \mathrm{H}_{6}$ (ref. 46) in ZIF-8 were computed by molecular dynamics simulations. All these simulations were generally carried out for singlecomponent gases since calculating diffusivities of gas mixtures is computationally demanding. We recently reported diffusion coefficients of $\mathrm{C}_{2} \mathrm{H}_{6} / \mathrm{C}_{2} \mathrm{H}_{4}$ and $\mathrm{C}_{2} \mathrm{H}_{6} / \mathrm{CH}_{4}$ binary mixtures in 5 different MOFs and using this diffusion data we predicted membrane selectivities and gas permeabilities of the 5 MOFs for $\mathrm{C}_{2} \mathrm{H}_{6}$ separations. ${ }^{27}$ Our results on a small number of MOFs demonstrated that MOFs are promising membranes for preferential separation of $\mathrm{C}_{2} \mathrm{H}_{6}$ from $\mathrm{C}_{2} \mathrm{H}_{4}$ due to their higher selectivities and higher gas permeabilities compared to zeolites and polymers.

The literature we summarized above shows that current studies on MOF membranes for $\mathrm{C}_{2} \mathrm{H}_{6}$ separations examine only a few types of structures. There is currently no large-scale computational study to identify the separation performances of different MOFs for $\mathrm{C}_{2} \mathrm{H}_{6} / \mathrm{C}_{2} \mathrm{H}_{4}$ and $\mathrm{C}_{2} \mathrm{H}_{6} / \mathrm{CH}_{4}$ mixtures. Considering the large variety and number of available MOFs, there may be many existing MOFs with better separation performances, high membrane selectivities and high gas permeabilities. In order to identify membrane-based $\mathrm{C}_{2} \mathrm{H}_{6}$ separation performances of a large number of MOFs, we used molecular simulations and computed adsorption equilibria and self-diffusivities of $\mathrm{C}_{2} \mathrm{H}_{6}$ / $\mathrm{C}_{2} \mathrm{H}_{4}$ and $\mathrm{C}_{2} \mathrm{H}_{6} / \mathrm{CH}_{4}$ mixtures in 175 different MOFs. Using this data, we predicted adsorption selectivity, diffusion selectivity, membrane selectivity and gas permeability of 175 MOFs both for $\mathrm{C}_{2} \mathrm{H}_{6} / \mathrm{C}_{2} \mathrm{H}_{4}$ and $\mathrm{C}_{2} \mathrm{H}_{6} / \mathrm{CH}_{4}$ separations. Results were compared with well-known membrane materials, polymers, zeolites and carbon molecular sieves to evaluate the potential of MOFs. Relations between adsorption selectivity, diffusion selectivity and membrane selectivity of MOFs were discussed to understand the individual effects of adsorption and diffusion on the membranes' performances. We finally examined the relations between easily computable structural properties such as pore size, surface area and porosity of MOFs and their selectivities to provide structureperformance relationships that can serve as a map for experimental synthesis of new MOFs with better gas separation performances.

\section{Computational details}

\subsection{MOFs}

We used the same MOF database that we considered in our previous work. ${ }^{27}$ This database was originally prepared using the solvent-free MOF database constructed by chung and coworkers ${ }^{47}$ and adding some well-known MOFs taken from our previous studies ${ }^{48}$ in order to cover widely studied subfamilies such as ZIFs, covalent organic frameworks (COFs), and bioMOFs. This database does not have any MOF with open metal sites (OMS) in order to eliminate the necessity of performing detailed quantum-level calculations to accurately define the specific interactions between $\mathrm{C}_{2} \mathrm{H}_{4}$ and OMS of MOFs as 
discussed in detail before..$^{27,49}$ We then refined our database to only include MOFs that have pore sizes (largest cavity diameters) larger than the kinetic diameters of the $\mathrm{C}_{2} \mathrm{H}_{6}, \mathrm{C}_{2} \mathrm{H}_{4}$ and $\mathrm{CH}_{4}$ molecules so that all these gases can enter into the MOFs' pores and diffuse. After this elimination, we ended up with 175 different MOF structures. All crystal structures of MOFs were taken from the Cambridge Crystallographic Data Centre (CCDC) ${ }^{50}$ The complete list of MOFs including the CCDC names and common names is given in Table S1 of ESI. $\dagger$ Structural properties of materials such as pore limiting diameter (PLD), largest cavity diameter (LCD), pore volume, porosity, and surface area were computed using Poreblazer algorithm ${ }^{51}$ in which the Dreiding force field ${ }^{52}$ was utilized. In this algorithm, $\mathrm{He}$ and $\mathrm{N}_{2}$ atoms were used as probe molecules for pore size and surface area calculations, respectively. The sigma parameters for $\mathrm{He}$ and $\mathrm{N}_{2}$ were used in their default values in the Poreblazer algorithm as $2.58 \AA$ and $3.31 \AA$, respectively. The cut-off distance and cubelet size were used as $12.8 \AA$ and $0.2 \AA$, respectively. The largest anticipated pore diameter was increased to $20 \AA$ and the size of the bin was decreased to $0.25 \AA$ in that algorithm.

\subsection{Molecular simulations}

Grand Canonical Monte Carlo (GCMC) ${ }^{53}$ simulations were used to compute binary adsorption isotherms of $\mathrm{C}_{2} \mathrm{H}_{6} / \mathrm{C}_{2} \mathrm{H}_{4}$ and $\mathrm{C}_{2} \mathrm{H}_{6} / \mathrm{CH}_{4}$ mixtures in MOFs. In a GCMC simulation, adsorbed amounts of each gas component were calculated by specifying the bulk pressure, temperature and composition of the bulk gas mixture. The Dreiding force field ${ }^{52}$ was used for the MOFs. In cases where the potential parameters of atoms were not available from the Dreiding force field, these parameters were taken from the Universal Force Field (UFF). ${ }^{54}$ These force fields were selected based on the results of our initial simulation studies that give a good agreement with the available experimental uptake data of $\mathrm{C}_{2} \mathrm{H}_{6}, \mathrm{C}_{2} \mathrm{H}_{4}$ and $\mathrm{CH}_{4}$ in various MOFs as reported in our previous work. ${ }^{27}$ Single-site spherical Lennard-Jones (LJ) 12-6 potential was used to model $\mathrm{CH}_{4}$ (ref. 55) whereas two-site spherical LJ potentials were used for $\mathrm{C}_{2} \mathrm{H}_{6}$ and $\mathrm{C}_{2} \mathrm{H}_{4}$ molecules following the literature (given Table $\mathrm{S} 2 \dagger$ ). ${ }^{25} \mathrm{C}_{2} \mathrm{H}_{6}$ and $\mathrm{C}_{2} \mathrm{H}_{4}$ molecules were described as uncharged united-atom models with one pseudo-atom representing $-\mathrm{CH}_{3}$ group and $-\mathrm{CH}_{2}$ group that was located at the position of carbon atom similar to the TraPPE united atom force field. ${ }^{55}$ Since the adsorbate molecules did not contain any dipole, the long-range electrostatic contribution was omitted following the previous studies in the literature. ${ }^{25}$ The cut-off distance for truncation of the intermolecular interactions was set to $12 \AA$ for GCMC simulations. A simulation box of $2 \times 2 \times 2$ crystallographic unit cells was used. Periodic boundary conditions were applied in all simulations. During the simulations, $1.5 \times 10^{7}$ steps were performed to guarantee the equilibration and $1.5 \times 10^{7}$ steps were performed to sample the desired properties.

Computing membrane properties of MOFs requires diffusivities of gas molecules in the pores of materials. In order to obtain self-diffusivities of $\mathrm{C}_{2} \mathrm{H}_{6} / \mathrm{C}_{2} \mathrm{H}_{4}$ and $\mathrm{C}_{2} \mathrm{H}_{6} / \mathrm{CH}_{4}$ mixtures in MOFs, we performed Equilibrium Molecular Dynamics (EMD) simulations. The initial states of EMD simulations with the appropriate gas loadings were obtained from the GCMC simulations and each system was equilibrated for 20 ps prior to taking data. The Nosé-Hoover thermostat was applied to run EMD simulations at NVT (constant number of molecules, volume and temperature) ensemble. ${ }^{53}$ At least 10 independent EMD simulations with a length of $16 \mathrm{~ns}$ were performed to compute self-diffusivities of gases at the given loadings. The estimated uncertainties of the self-diffusivities were at least one order of magnitude smaller than the reported diffusion coefficients. More details of using GCMC and EMD simulations to obtain adsorption data and diffusion coefficients in various MOFs can be found in our previous studies. ${ }^{56,57}$

Molecular simulations should be performed for multiple materials on time scales shorter than the same materials can be assessed experimentally. Since we considered a large number of MOF membranes in this work, we used rigid framework assumption. Almost all molecular simulations for MOF membranes in the literature used this assumption because it saves a significant amount of computational time. Recent studies showed that including lattice flexibility does not make any significant change in the gas adsorption results of MOFs that have pore sizes larger than the guest molecules. ${ }^{\mathbf{5 8}-60}$ Chmelik et al. could not find any evidence for gate-opening effect or another structural transitions of ZIF-8 upon adsorption of $\mathrm{C}_{2} \mathrm{H}_{6} / \mathrm{C}_{2} \mathrm{H}_{4}$ mixture. ${ }^{40}$ On the other hand, lattice flexibility can be important for the diffusion of large gas molecules in the MOFs having narrow windows. ${ }^{\mathbf{4 4}, 46}$ We recently carried out flexible EMD simulations to examine the effect of MOF's flexibility on the predicted membrane performance. ${ }^{61}$ Considering flexibility of the framework made a negligible effect on the gas permeability and selectivity of the MOFs having large pores whereas more pronounced changes were seen in gas permeabilities of the materials having narrow pores. Another recent study on Xe separations showed that flexibility should be considered in shape selective screening studies for the highest degree of accuracy and to achieve the best ranking of highperformance materials. ${ }^{62}$ Since MOFs considered in this work were specifically chosen to have larger pore diameters than the kinetic diameters of the three gas molecules we studied, flexibility effects were expected to be small and they were not taken into account for computational efficiency. The idea of our calculations is that once the potential value of a membrane material has been demonstrated by molecular simulations, further detailed studies such as flexible simulations can be performed to increase the precision of initial assessment.

\subsection{Calculation of membrane properties}

Adsorption selectivities $\left(S_{\text {ads }}\right.$ ) of MOFs for $\mathrm{C}_{2} \mathrm{H}_{6} / \mathrm{C}_{2} \mathrm{H}_{4}$ and $\mathrm{C}_{2} \mathrm{H}_{6}$ / $\mathrm{CH}_{4}$ separations were calculated using the results of mixture GCMC simulations as we previously reported. ${ }^{27} S_{\text {ads }}$ is defined as the ratio of compositions of the adsorbed gases $(x)$ in the adsorbent material normalized by the ratio of bulk phase compositions $(y)$ of component $i$ to component $j$ :

$$
S_{\operatorname{ads}(i / j)}=\left(x_{i} / x_{j}\right) /\left(y_{i} / y_{j}\right)
$$


Adsorption selectivities of MOFs were computed at 10 bar, $298 \mathrm{~K}$ for equimolar $\mathrm{C}_{2} \mathrm{H}_{6} / \mathrm{C}_{2} \mathrm{H}_{4}$ and $\mathrm{C}_{2} \mathrm{H}_{6} / \mathrm{CH}_{4}$ mixtures. The ratio of self-diffusivities of gases obtained from the EMD simulations was used to define the diffusion selectivity of MOFs. Diffusion selectivity, $\left(S_{\text {diff }}\right)$ was calculated as the ratio of the self-diffusivities $\left(D_{i \text {,self }}\right)$ of each gas component in the binary mixture where $c_{i}$ represents the corresponding adsorbed loading of gas species $i$ calculated from the GCMC simulations at 10 bar, $298 \mathrm{~K}$ :

$$
S_{\mathrm{diff}(i / j)}=\frac{D_{i, \text { self }}\left(c_{i}, c_{j}\right)}{D_{j, \text { self }}\left(c_{i}, c_{j}\right)}
$$

Once the adsorption and diffusion selectivities of MOFs were computed for a given gas mixture, membrane selectivity $\left(S_{\text {mem }}\right)$, also known as permeation selectivity, was calculated as the multiplication of adsorption selectivity and diffusion selectivity at a membrane feed pressure of 10 bar as described in the literature. ${ }^{56}$ The validity of this model was shown by comparing its predictions with the experimentally measured selectivity and permeability data of MOF membranes for various gas separations in previous studies. ${ }^{\mathbf{5 6}}$

$$
S_{\mathrm{mem}(i / j)}=S_{\mathrm{ads}(i / j)} \times S_{\mathrm{diff}(i / j)}
$$

Not only high selectivity but also high gas permeability is required for an efficient and economic membrane process. Therefore, we also computed gas permeabilities through MOFs using the following expression, ${ }^{63}$

$$
P_{i}=\frac{\phi \times D_{i, \text { self }} \times c_{i}}{f_{i}}
$$

where $P_{i}, \phi, D_{i, \text { self }}, c_{i}$ and $f_{i}$ represent the permeability of the component $i\left(\mathrm{~mol} \mathrm{~m}{ }^{-1} \mathrm{~s}^{-1} \mathrm{~Pa}^{-1}\right)$, the porosity of MOFs (given in Table $\mathrm{S} 1 \dagger)$, the self-diffusivity of the component $i$ in the mixture $\left(\mathrm{m}^{2} \mathrm{~s}^{-1}\right)$, the concentration of component $i$ at the upstream face of the membrane $\left(\mathrm{mol} \mathrm{m}^{-3}\right)$ and the bulk phase fugacity of the component $i(\mathrm{~Pa})$, respectively. The bulk gas compositions of $\mathrm{C}_{2} \mathrm{H}_{6} / \mathrm{C}_{2} \mathrm{H}_{4}$ and $\mathrm{C}_{2} \mathrm{H}_{6} / \mathrm{CH}_{4}$ mixtures were assumed to be equimolar in all molecular simulations because Guo et al. recently showed that composition does not strongly affect the $\mathrm{C}_{2} \mathrm{H}_{6}$ selectivity of a MOF material. ${ }^{24}$ The accuracy of our computational approach to predict the membrane performances of MOFs for various gas mixtures using the GCMC and EMD data as explained above was shown in several of our previous studies by comparing the results of simulations with the experiments. ${ }^{64,65}$ We recently reported remarkably well agreement between our simulations and experimental measurements both for single-component and mixture $\mathrm{CH}_{4}$ permeability through different MOF membranes including MOF-5, ZIF-78, ZIF-95. ${ }^{61}$

\section{Results and discussion}

\subsection{Membrane properties of MOFs}

We validated the accuracy of our GCMC simulations to predict the adsorption of $\mathrm{C}_{2} \mathrm{H}_{6}, \mathrm{C}_{2} \mathrm{H}_{4}$ and $\mathrm{CH}_{4}$ in various MOFs such as CuBTC, PCN-16, Co-MOF-74 and Mg-MOF-74 by comparing results of our molecular simulations with the available experimental data of different research groups in our previous work. ${ }^{27}$ In this work, we aimed to validate the accuracy of our EMD simulations for the diffusivity of $\mathrm{C}_{2} \mathrm{H}_{6}$ and $\mathrm{CH}_{4}$ in the MOFs' pores. There is limited information about the diffusivity of these gases in MOFs due to the difficulty of measurement of self-diffusivity using purely experimental techniques and high computational demands of molecular simulations. Table 1 compares $\mathrm{C}_{2} \mathrm{H}_{6}$ and $\mathrm{CH}_{4}$ diffusivities calculated from our molecular simulations with the available experimental and computational data taken from the literature. Our simulated data for $\mathrm{C}_{2} \mathrm{H}_{6}$ and $\mathrm{CH}_{4}$ diffusivities in MOFs agreed well with the previous simulation studies of different research groups. $\mathrm{C}_{2} \mathrm{H}_{6}$ diffusivities in MOF-5 predicted by our molecular simulations agreed well with the experimental measurements of Stallmach et $a l .{ }^{38}$ and Ford et $a l .{ }^{39}$ whereas simulations predicted an order of magnitude slower $\mathrm{CH}_{4}$ diffusivity in MOF-5 compared to the experiments. This discrepancy was attributed to the imperfections in the micropore structure which influenced the experimental studies but which were not taken into account in the EMD simulations. ${ }^{38,39}$ Overall, the good agreement between our simulations and reported values in the literature for diffusion of $\mathrm{C}_{2} \mathrm{H}_{6}$ and $\mathrm{CH}_{4}$ in MOFs suggests that simulated diffusion coefficients can be used to model gas transport through the MOF membranes.

Combining adsorption data obtained from the GCMC simulations and diffusion data obtained from the EMD simulations, we computed selectivity and permeability of MOF membranes for $\mathrm{C}_{2} \mathrm{H}_{6} / \mathrm{C}_{2} \mathrm{H}_{4}$ and $\mathrm{C}_{2} \mathrm{H}_{6} / \mathrm{CH}_{4}$ mixture separations as shown in Fig. 1. In order to compare MOFs with traditional membrane materials, we collected selectivity and permeability data of zeolites, carbon molecular sieves (CMSs) and polymers for $\mathrm{C}_{2} \mathrm{H}_{6}$ / $\mathrm{C}_{2} \mathrm{H}_{4}$ separations. At that point it is important to reiterate that membrane materials that preferentially select $\mathrm{C}_{2} \mathrm{H}_{6}$ over $\mathrm{C}_{2} \mathrm{H}_{4}$ are very scarce. Zeolites, CMSs and polymers are generally $\mathrm{C}_{2} \mathrm{H}_{4}$ selective. In order to be consistent with the literature data, we showed $\mathrm{C}_{2} \mathrm{H}_{4} / \mathrm{C}_{2} \mathrm{H}_{6}$ selectivity and $\mathrm{C}_{2} \mathrm{H}_{4}$ permeability of MOF membranes in Fig. 1(a). Traditional polymeric membranes, such as Matrimid, 4,4' -(hexafluoroisopropylidene)dipthalicanhydride2,4,6-trimethyl-1,3-phenylene diamine (6FDA-DAM), 4,4' -(hexafluoroisopropylidene)dipthalicanhydride:3,3',4,4'-biphenyltetracarboxylic dianhydride-2,4,6-trimethyl-1,3-phenylene diamine (6FDA:BPDA-DAM) selectively separate $\mathrm{C}_{2} \mathrm{H}_{4}$ from $\mathrm{C}_{2} \mathrm{H}_{6}$, generally due their sorption selectivities. ${ }^{67}$ The black solid line in Fig. 1(a) represents the experimental $\mathrm{C}_{2} \mathrm{H}_{4} / \mathrm{C}_{2} \mathrm{H}_{6}$ upper bound for polymers which was established by Rungta et $a l^{67}$ based on the pure gas permeability data, similar to the Robeson's upper bound. ${ }^{68}$ Polymeric membranes are mostly located below this bound and it is highly desired to identify new membrane materials that can exceed this bound by exhibiting higher selectivity and/or higher permeability than polymers. Since MOFs are highly porous materials compared to polymers, $\mathrm{C}_{2} \mathrm{H}_{4}$ permeabilities of MOF membranes are significantly higher than those of polymers. According to the upper bound, the $\mathrm{C}_{2} \mathrm{H}_{4}$ permeabilities of polymeric membranes are in the range of $0.1-10^{4}$ Barrer whereas MOF membranes we considered in this work exhibit $\mathrm{C}_{2} \mathrm{H}_{4}$ permeabilities in the range of $42-6.75 \times 10^{5}$ Barrer. Therefore, we 
Table 1 Comparison of simulated self-diffusivities of gases in MOFs with the literature

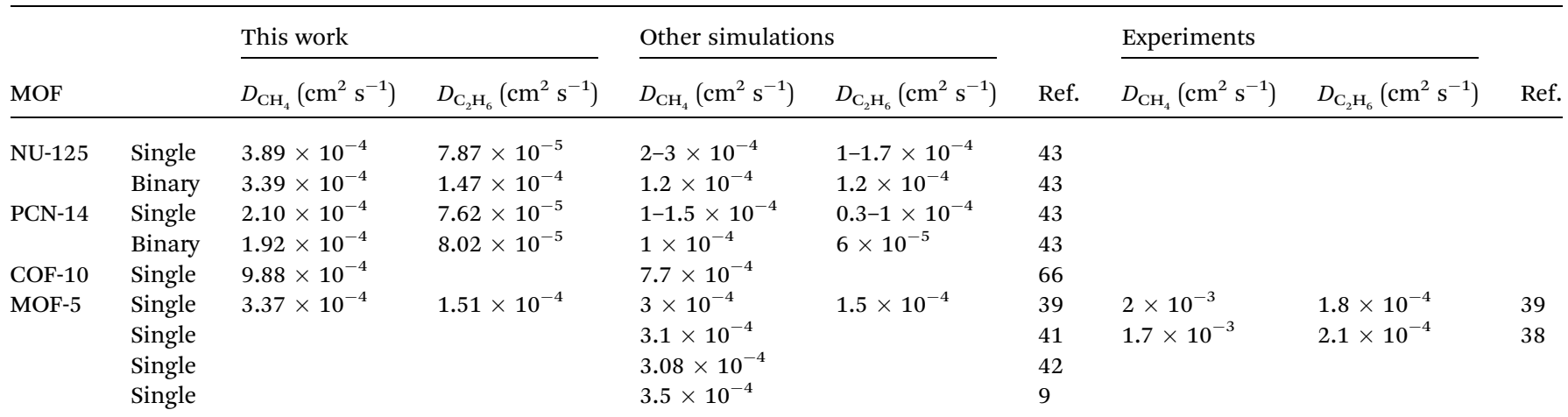

extrapolated the Robeson's upper bound with a dashed line in Fig. 1(a) to show the high $\mathrm{C}_{2} \mathrm{H}_{4}$ permeabilities of MOFs. In fact, 4 MOFs, YUTYOC, IDIWOH, OWITAQ and OWITUQ were found to exceed the upper bound due to their high $\mathrm{C}_{2} \mathrm{H}_{4}$ permeabilities.

The red solid line shows the selectivity preference of the membranes in Fig. 1(a). MOFs located above (below) this line are $\mathrm{C}_{2} \mathrm{H}_{4}\left(\mathrm{C}_{2} \mathrm{H}_{6}\right)$ selective. A significant number of MOF membranes was identified to show $\mathrm{C}_{2} \mathrm{H}_{6}$ selectivity over $\mathrm{C}_{2} \mathrm{H}_{4}$ and these MOFs were located below the red line. Well-known zeolites such as zeolite $4 \mathrm{~A}$, zeolite $5 \mathrm{~A}$, SAPO-34 and CMSs are $\mathrm{C}_{2} \mathrm{H}_{4}$ selective membranes in $\mathrm{C}_{2} \mathrm{H}_{6} / \mathrm{C}_{2} \mathrm{H}_{4}$ separations. ${ }^{67}$ For example, zeolite $4 \mathrm{~A}$ membrane has $\mathrm{C}_{2} \mathrm{H}_{4}$ selectivity of 3 and $\mathrm{C}_{2} \mathrm{H}_{4}$ permeability of 0.1 Barrer whereas the MOFs we considered in this work are mostly $\mathrm{C}_{2} \mathrm{H}_{6}$ selective with significantly higher $\mathrm{C}_{2} \mathrm{H}_{4}$ permeabilities. ${ }^{67}$ The maximum $\mathrm{C}_{2} \mathrm{H}_{4}$ selectivity of CMS membranes was reported to be around 10 and their maximum $\mathrm{C}_{2} \mathrm{H}_{4}$ permeabilities were around 1000 Barrer. ${ }^{69-71} \mathrm{~A}$ recent study reported that a ZIF-8-filled 6FDA-DAM MMM exhibit $\mathrm{C}_{2} \mathrm{H}_{4}$ selectivity of 3.2 and permeability of 72.9 Barrer depending on the ZIF loading in the polymer. ${ }^{72}$ All these comparisons show that $\mathrm{C}_{2} \mathrm{H}_{4}$ permeability of MOF membranes are significantly higher than that of zeolite $4 \mathrm{~A}$, zeolite 5A, SAPO34, and ZIF-8-filled MMM. Since majority of the MOFs we examined in this work are $\mathrm{C}_{2} \mathrm{H}_{6}$ selective, we additionally showed the $\mathrm{C}_{2} \mathrm{H}_{6}$ selectivity and $\mathrm{C}_{2} \mathrm{H}_{6}$ permeability of MOFs in Fig. 1(b). This figure shows that MOF membranes can selectively separate $\mathrm{C}_{2} \mathrm{H}_{6}$ from $\mathrm{C}_{2} \mathrm{H}_{4}$ with high selectivity. 169 out of 175 MOFs are $\mathrm{C}_{2} \mathrm{H}_{6}$ selective with selectivities in the range of 1.0-5.4. Among these MOFs, EYOPUE has the highest $\mathrm{C}_{2} \mathrm{H}_{6}$ / $\mathrm{C}_{2} \mathrm{H}_{4}$ selectivity (5.4) and OWITIY has the highest $\mathrm{C}_{2} \mathrm{H}_{6}$ permeability $\left(1.04 \times 10^{6}\right.$ Barrer $)$. Selectivity of 11 MOFs was found to be slightly larger than unity which means they do not have a strong preference for $\mathrm{C}_{2} \mathrm{H}_{6}$ or $\mathrm{C}_{2} \mathrm{H}_{4}$ and therefore they cannot be used as selective membranes for $\mathrm{C}_{2} \mathrm{H}_{6} / \mathrm{C}_{2} \mathrm{H}_{4}$ separations. A small number of MOF membranes (6 out of 175) was identified to show low/mediocre $\mathrm{C}_{2} \mathrm{H}_{4}$ selectivity over $\mathrm{C}_{2} \mathrm{H}_{6}$ and located below the red line.

Fig. 1(c) represents $\mathrm{C}_{2} \mathrm{H}_{6} / \mathrm{CH}_{4}$ selectivity and $\mathrm{C}_{2} \mathrm{H}_{6}$ permeability of MOF membranes. Although an upper bound is not established yet, several polymeric membranes were tested for $\mathrm{C}_{2} \mathrm{H}_{6} / \mathrm{CH}_{4}$ separation and we collected this data from the literature to compare MOF membranes with polymers..$^{3,71-76}$ Most of the polymeric membranes exhibit $\mathrm{C}_{2} \mathrm{H}_{6}$ permeabilities between 10-100 Barrer and $\mathrm{C}_{2} \mathrm{H}_{6} / \mathrm{CH}_{4}$ selectivities between 0.7 and 3 . Only polydimethylsiloxane (PDMS) and polympentanamer (PPM) membranes show higher $\mathrm{C}_{2} \mathrm{H}_{6}$ permeabilities reaching to 2070 Barrer (ref. 73) and 3900 Barrer, ${ }^{74}$ respectively. Most of the MOFs studied in this work exhibit higher $\mathrm{C}_{2} \mathrm{H}_{6}$ permeabilities and higher $\mathrm{C}_{2} \mathrm{H}_{6} / \mathrm{CH}_{4}$ selectivities than these polymers. Among 175 MOFs, all the MOFs except 3 of them (XENZUN, GITVAH and YARYEV) were identified to be $\mathrm{C}_{2} \mathrm{H}_{6}$ selective over $\mathrm{CH}_{4}$ and their $\mathrm{C}_{2} \mathrm{H}_{6}$ permeabilities were computed to be in the range of 49.5-1.39 $\times 10^{6}$ Barrer. The most selective MOF for $\mathrm{C}_{2} \mathrm{H}_{6} / \mathrm{CH}_{4}$ separation was identified as NEXXIZ, with a selectivity of 20.5 and $\mathrm{C}_{2} \mathrm{H}_{6}$ permeability of $2.12 \times 10^{5}$ Barrer. OWITAQ was identified as the most permeable MOF with $\mathrm{C}_{2} \mathrm{H}_{6}$ permeability of $1.39 \times 10^{6}$ Barrer and $\mathrm{C}_{2} \mathrm{H}_{6} / \mathrm{CH}_{4}$ selectivity of 6 . All these results indicate that $\mathrm{MOFs}$ are highly promising membrane materials for preferential separation of $\mathrm{C}_{2} \mathrm{H}_{6}$ from $\mathrm{CH}_{4}$.

Combination of adsorption and diffusion selectivity determines the membrane selectivity of a MOF. In order to evaluate the individual effects of gas adsorption and diffusion on the membrane performance of MOFs, we examined the relation between adsorption, diffusion, and membrane selectivity in Fig. 2. All selectivities were computed for equimolar gas mixtures. The colored dots in Fig. 2(a) show the distribution of the diffusion selectivities of MOFs for $\mathrm{C}_{2} \mathrm{H}_{6} / \mathrm{C}_{2} \mathrm{H}_{4}$ mixture. The LJ energy parameter was higher for $\mathrm{C}_{2} \mathrm{H}_{6}\left(\varepsilon_{\mathrm{C}_{2} \mathrm{H}_{6}} / k_{\mathrm{B}}=108 \mathrm{~K}\right)$ than $\mathrm{C}_{2} \mathrm{H}_{4}\left(\varepsilon_{\mathrm{C}_{2} \mathrm{H}_{4}} / k_{\mathrm{B}}=92.8 \mathrm{~K}\right)$ to reflect stronger dispersion interactions. Since $\mathrm{C}_{2} \mathrm{H}_{6}$ is energetically preferred over $\mathrm{C}_{2} \mathrm{H}_{4}, \mathrm{C}_{2} \mathrm{H}_{6}$ $\left(\mathrm{C}_{2} \mathrm{H}_{4}\right)$ is the strongly (weakly) adsorbed component in all MOFs. Therefore, adsorption selectivities favor $\mathrm{C}_{2} \mathrm{H}_{6}$ over $\mathrm{C}_{2} \mathrm{H}_{4}$ $\left(\mathrm{C}_{2} \mathrm{H}_{6} / \mathrm{C}_{2} \mathrm{H}_{4}\right.$ selectivity $\left.>1\right)$ for all MOFs. Diffusion selectivities favor $\mathrm{C}_{2} \mathrm{H}_{4}\left(\mathrm{C}_{2} \mathrm{H}_{6} / \mathrm{C}_{2} \mathrm{H}_{4}\right.$ selectivity $\left.<1\right)$ in most of the MOFs since $\mathrm{C}_{2} \mathrm{H}_{4}$ molecules diffuse faster than $\mathrm{C}_{2} \mathrm{H}_{6}$ molecules. $\mathrm{C}_{2} \mathrm{H}_{4}$ molecules are lighter, smaller and weakly adsorbed into the pores of MOFs which leads to faster diffusion of $\mathrm{C}_{2} \mathrm{H}_{4}$ than $\mathrm{C}_{2} \mathrm{H}_{6}$. For 50 MOFs shown by red color, the diffusion selectivity for $\mathrm{C}_{2} \mathrm{H}_{6}$ over $\mathrm{C}_{2} \mathrm{H}_{4}$ is ranged from 0.45 to 0.83 . Since the membrane selectivity was estimated as the multiplication of the adsorption and diffusion selectivities, the predicted membrane selectivities of these MOFs for $\mathrm{C}_{2} \mathrm{H}_{6}$ are lower than their adsorption selectivities as shown in Fig. 2(a). In other words, these MOFs are more useful in adsorption-based $\mathrm{C}_{2} \mathrm{H}_{6} / \mathrm{C}_{2} \mathrm{H}_{4}$ 

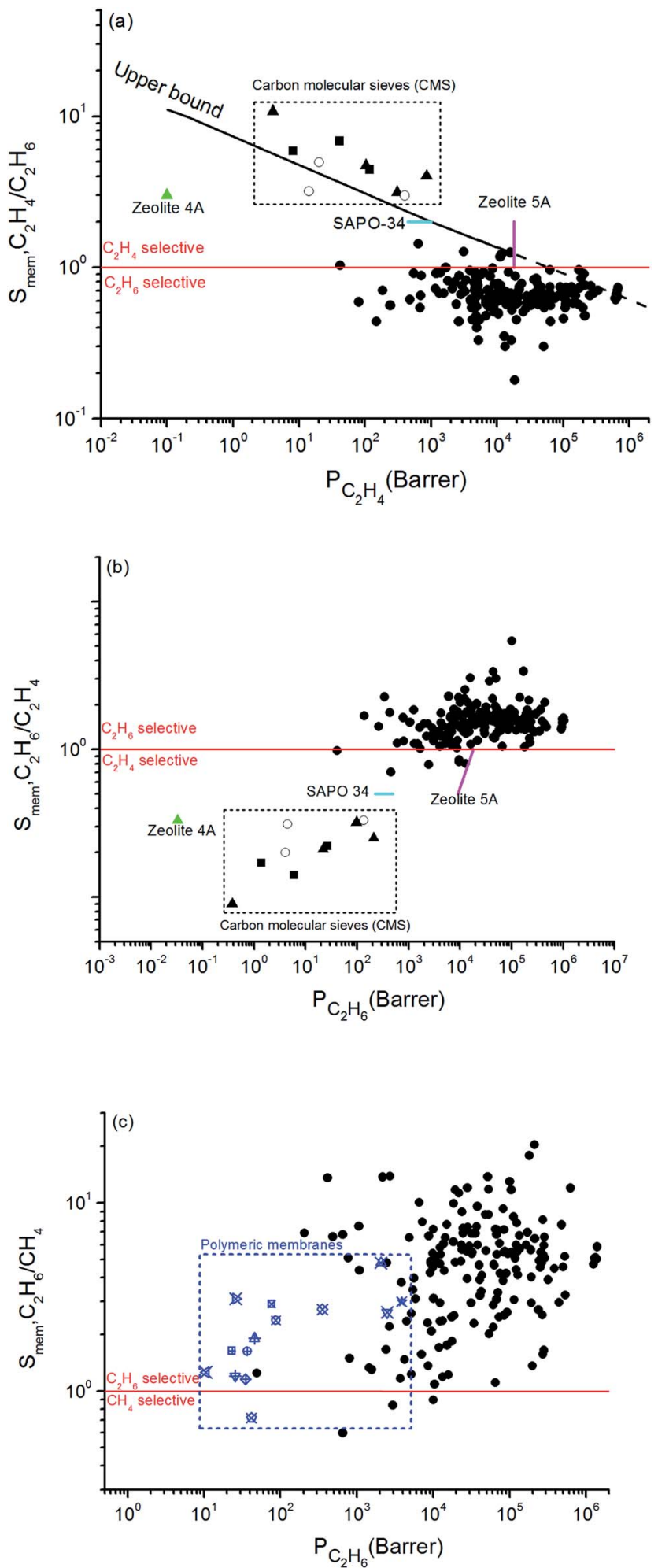

Fig. 1 Selectivity and permeability of MOFs for (a) $\mathrm{C}_{2} \mathrm{H}_{4} / \mathrm{C}_{2} \mathrm{H}_{6}$, (b) $\mathrm{C}_{2} \mathrm{H}_{6} / \mathrm{C}_{2} \mathrm{H}_{4}$, (c) $\mathrm{C}_{2} \mathrm{H}_{6} / \mathrm{CH}_{4}$ separations. Data for $\mathrm{CMSs}$ shown within the box ${ }^{69-71}$ and data for zeolites shown with color symbols ${ }^{75-77}$ were taken from the literature in (a) and (b). Data for polymeric membranes shown with blue symbols in (c) were taken from the literature. ${ }^{34,73,74,78-81}$

separations than in membrane-based separations in terms of $\mathrm{C}_{2} \mathrm{H}_{6}$ selectivity. 113 MOFs shown by green color have diffusion selectivities around unity (0.83-1.10), which means diffusion
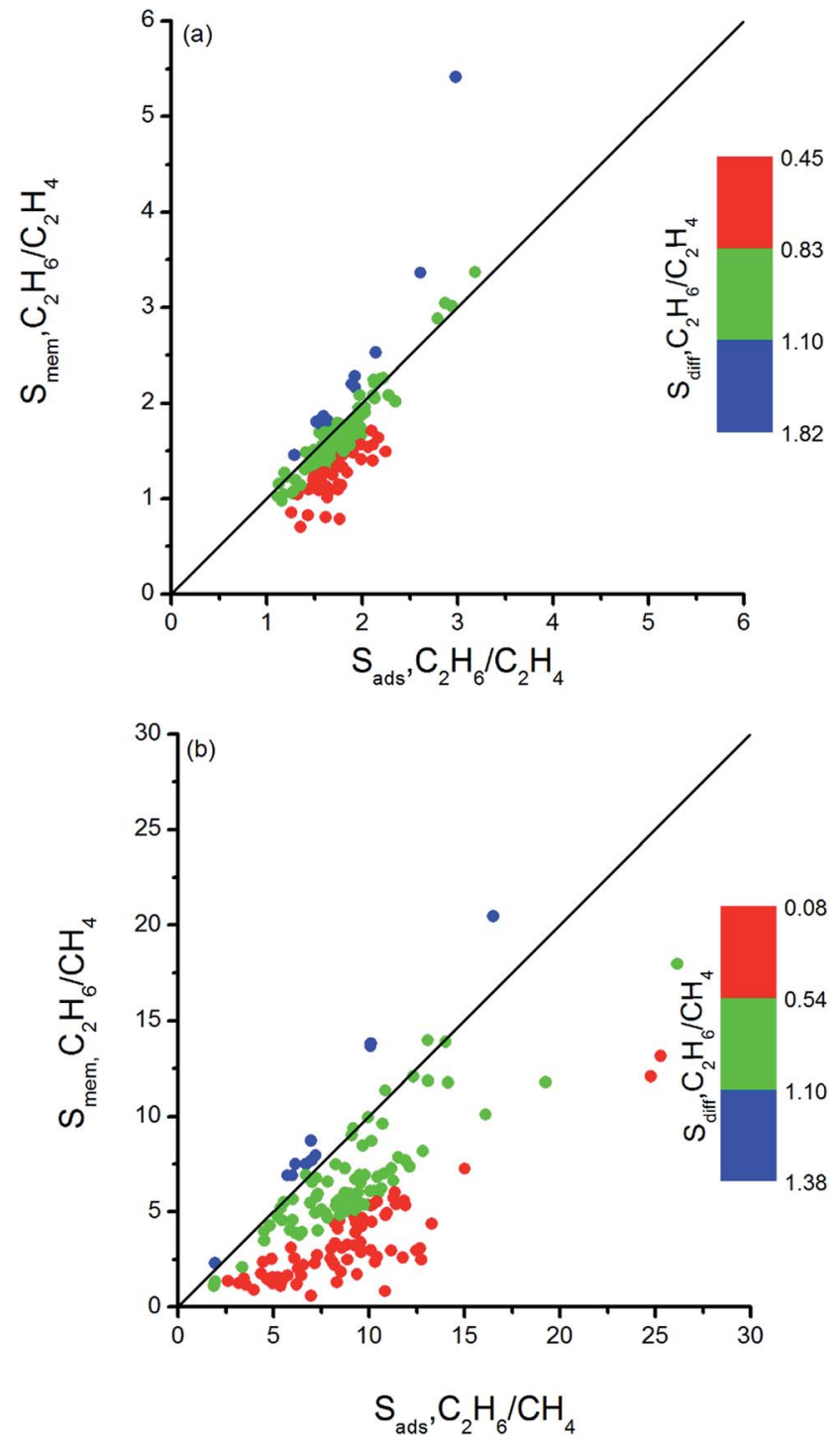

Fig. 2 Adsorption, diffusion and membrane selectivities of MOFs for (a) $\mathrm{C}_{2} \mathrm{H}_{6} / \mathrm{C}_{2} \mathrm{H}_{4}$ and (b) $\mathrm{C}_{2} \mathrm{H}_{6} / \mathrm{CH}_{4}$ separations.

does not strongly favor one gas species over other in the mixture. Since diffusion selectivities are close to one, membrane selectivities of these MOFs are only slightly lower than their adsorption selectivities. On the other hand, 12 of the MOFs shown by blue color exhibit diffusion selectivities higher than unity (1.11-1.82). That means self-diffusion coefficient of $\mathrm{C}_{2} \mathrm{H}_{6}$ is slightly higher than $\mathrm{C}_{2} \mathrm{H}_{4}$. In this case, both adsorption and diffusion favors the same component, $\mathrm{C}_{2} \mathrm{H}_{6}$ over $\mathrm{C}_{2} \mathrm{H}_{4}$ in the mixture. As a result, membrane selectivities of these MOFs are higher than their adsorption-based selectivities. In fact, it is highly desired to find materials in which both adsorption and diffusion favor the same gas component and lead to high membrane selectivities. Table 2 summarizes the top ten $\mathrm{C}_{2} \mathrm{H}_{6}$ selective MOF membranes together with their adsorption, diffusion, membrane selectivities in addition to the selfdiffusivities of each gas species in these materials. Both adsorption and diffusion selectivities of the MOFs listed in 
Table 2 Top ten MOF membranes for $\mathrm{C}_{2} \mathrm{H}_{6} / \mathrm{C}_{2} \mathrm{H}_{4}$ separation

\begin{tabular}{|c|c|c|c|c|c|c|c|}
\hline MOF & $S_{\text {ads, }} \mathrm{C}_{2} \mathrm{H}_{6} / \mathrm{C}_{2} \mathrm{H}_{4}$ & $D_{\mathrm{C}_{2} \mathrm{H}_{6}}\left(\mathrm{~cm}^{2} \mathrm{~s}^{-1}\right)$ & $D_{\mathrm{C}_{2} \mathrm{H}_{4}}\left(\mathrm{~cm}^{2} \mathrm{~s}^{-1}\right)$ & $\begin{array}{l}S_{\text {diff }} \\
\mathrm{C}_{2} \mathrm{H}_{6} / \mathrm{C}_{2} \mathrm{H}_{4}\end{array}$ & $\begin{array}{l}S_{\mathrm{mem}}, \\
\mathrm{C}_{2} \mathrm{H}_{6} / \mathrm{C}_{2} \mathrm{H}_{4}\end{array}$ & $P_{\mathrm{C}_{2} \mathrm{H}_{6}}$ (Barrer) & $P_{\mathrm{C}_{2} \mathrm{H}_{4}}$ (Barrer) \\
\hline EYOPUE & 2.98 & $1.45 \times 10^{-4}$ & $7.97 \times 10^{-5}$ & 1.82 & 5.41 & $1.01 \times 10^{5}$ & $1.86 \times 10^{4}$ \\
\hline EYOPOY & 3.18 & $1.62 \times 10^{-4}$ & $1.53 \times 10^{-4}$ & 1.06 & 3.37 & $1.73 \times 10^{5}$ & $5.12 \times 10^{4}$ \\
\hline AMAFUQ & 2.61 & $8.09 \times 10^{-5}$ & $6.27 \times 10^{-5}$ & 1.29 & 3.36 & $4.42 \times 10^{4}$ & $1.32 \times 10^{4}$ \\
\hline YUVSUE & 2.87 & $1.56 \times 10^{-5}$ & $1.47 \times 10^{-5}$ & 1.06 & 3.04 & $1.60 \times 10^{4}$ & $5.25 \times 10^{3}$ \\
\hline CAYDOX & 2.94 & $1.28 \times 10^{-4}$ & $1.25 \times 10^{-4}$ & 1.02 & 3.01 & $4.95 \times 10^{4}$ & $1.64 \times 10^{4}$ \\
\hline CAYGIU & 2.79 & $9.65 \times 10^{-5}$ & $9.34 \times 10^{-5}$ & 1.03 & 2.88 & $3.71 \times 10^{4}$ & $1.29 \times 10^{4}$ \\
\hline BUSNAF & 2.14 & $2.84 \times 10^{-5}$ & $2.41 \times 10^{-5}$ & 1.18 & 2.53 & $1.24 \times 10^{4}$ & $4.92 \times 10^{3}$ \\
\hline TUSGUJ & 1.92 & $3.80 \times 10^{-6}$ & $3.19 \times 10^{-6}$ & 1.19 & 2.28 & $6.05 \times 10^{3}$ & $2.65 \times 10^{3}$ \\
\hline UHAXUW & 2.22 & $6.58 \times 10^{-7}$ & $6.45 \times 10^{-7}$ & 1.02 & 2.26 & $3.40 \times 10^{2}$ & $1.50 \times 10^{2}$ \\
\hline NEXXIZ & 2.18 & $1.27 \times 10^{-4}$ & $1.23 \times 10^{-4}$ & 1.03 & 2.25 & $1.45 \times 10^{5}$ & $6.44 \times 10^{4}$ \\
\hline
\end{tabular}

Table 2 are higher than 1 , which means $\mathrm{C}_{2} \mathrm{H}_{6}$ is favored over $\mathrm{C}_{2} \mathrm{H}_{4}$ by both mechanisms. For example, EYOPUE has both high adsorption selectivity and high diffusion selectivity for $\mathrm{C}_{2} \mathrm{H}_{6}$ over $\mathrm{C}_{2} \mathrm{H}_{4}$. As a result it was identified as the most selective MOF membrane. Therefore, it is more useful to utilize the MOFs listed in Table 2 as membranes rather than as adsorbents for selective separation of $\mathrm{C}_{2} \mathrm{H}_{6}$ from $\mathrm{C}_{2} \mathrm{H}_{4}$.

It is interesting to discuss the MOFs for which the diffusion selectivity for $\mathrm{C}_{2} \mathrm{H}_{4}$ overcompensates the adsorption selectivity for $\mathrm{C}_{2} \mathrm{H}_{6}$ and makes the membrane $\mathrm{C}_{2} \mathrm{H}_{4}$ selective. We listed adsorption, diffusion, membrane selectivities and gas permeabilities of the $\mathrm{C}_{2} \mathrm{H}_{4}$ selective MOFs in Table 3. All these five MOFs are weakly selective for $\mathrm{C}_{2} \mathrm{H}_{4}$. For example, XENZUN was predicted to show the highest membrane selectivity. Adsorption weakly favors $\mathrm{C}_{2} \mathrm{H}_{6}$ over $\mathrm{C}_{2} \mathrm{H}_{4}$ in this MOF whereas diffusion favors $\mathrm{C}_{2} \mathrm{H}_{4}$ over $\mathrm{C}_{2} \mathrm{H}_{6}$ and dominates the adsorption selectivity. AVEROJ has a low $\mathrm{C}_{2} \mathrm{H}_{4} / \mathrm{C}_{2} \mathrm{H}_{6}$ adsorption selectivity but the diffusion selectivity strongly favors $\mathrm{C}_{2} \mathrm{H}_{4}$ over $\mathrm{C}_{2} \mathrm{H}_{6}$ and makes the membrane $\mathrm{C}_{2} \mathrm{H}_{4}$ selective. KEXFAU has the highest adsorption selectivity for $\mathrm{C}_{2} \mathrm{H}_{4} / \mathrm{C}_{2} \mathrm{H}_{6}$ separation as can be seen from Table 3, but its diffusion selectivity is close to unity making the membrane weakly selective for $\mathrm{C}_{2} \mathrm{H}_{4}$. These examples signify the importance of diffusion selectivity in governing membrane's separation performance. If the adsorption selectivity does not strongly favor one component in the mixture, then diffusion selectivity determines the membrane's gas separation performance.

Similar selectivity analysis was done for $\mathrm{C}_{2} \mathrm{H}_{6} / \mathrm{CH}_{4}$ separation in Fig. 2(b). Adsorption strongly favors $\mathrm{C}_{2} \mathrm{H}_{6}$ and strongly adsorbed $\mathrm{C}_{2} \mathrm{H}_{6}$ molecules move slower than weakly adsorbed, lighter $\mathrm{CH}_{4}$ molecules. As a result, diffusion selectivity favors $\mathrm{CH}_{4}$ over $\mathrm{C}_{2} \mathrm{H}_{6}$ and becomes less than 1 for almost all MOFs as shown by red and green points in Fig. 2(b). Since adsorption strongly favors $\mathrm{C}_{2} \mathrm{H}_{6}$ and diffusion weakly favors $\mathrm{CH}_{4}$, membrane-based $\mathrm{C}_{2} \mathrm{H}_{6}$ selectivities of MOFs are less than their adsorption-based selectivities. There are 11 MOFs shown by blue color in Fig. 2(b) in which diffusivity of $\mathrm{C}_{2} \mathrm{H}_{6}$ is slightly higher than the diffusivity of $\mathrm{CH}_{4}$. Our EMD simulations showed that gas molecules generally diffuse only in one direction in these MOFs and the high number of slowly diffusing $\mathrm{C}_{2} \mathrm{H}_{6}$ molecules hinders the fast diffusion of $\mathrm{CH}_{4}$ molecules in the pores. As a result, diffusion selectivities are around 1.1-1.3 and these MOFs are promising membrane materials since both adsorption and diffusion favors the same component $\mathrm{C}_{2} \mathrm{H}_{6}$ over $\mathrm{CH}_{4}$. Performances of the top ten promising MOF membranes for selective separation of $\mathrm{C}_{2} \mathrm{H}_{6}$ from $\mathrm{CH}_{4}$ were summarized in Table 4. For example, adsorption and diffusion favor $\mathrm{C}_{2} \mathrm{H}_{6}$ over $\mathrm{CH}_{4}$ in NEXXIZ, TIRQOB, ZUQPOQ, UHAXUW whereas high adsorption selectivity towards $\mathrm{C}_{2} \mathrm{H}_{6}$ dominates the diffusion selectivity towards $\mathrm{CH}_{4}$ in other MOFs as shown in Table 4.

As we discussed above, some MOFs are promising for adsorption-based gas separations whereas some others are good candidates for membrane-based gas separations. We aimed to identify the MOFs that can be used both as effective adsorbents and membranes for the preferential separation of $\mathrm{C}_{2} \mathrm{H}_{6}$ from $\mathrm{C}_{2} \mathrm{H}_{4}$ and $\mathrm{CH}_{4}$. Selectivity is generally considered as the most critical factor to assess equilibrium and kinetic-based separation performances of materials. High adsorption selectivity is desired for adsorbents whereas both high selectivity and permeability are required for membranes. Therefore, we considered these three performance metrics, adsorption selectivity, membrane selectivity and permeability of the desired gas in order to identify the most promising MOFs that can be used both as adsorbents and membranes. For $\mathrm{C}_{2} \mathrm{H}_{6} / \mathrm{C}_{2} \mathrm{H}_{4}$ separation,

Table 3 Top MOF membranes for $\mathrm{C}_{2} \mathrm{H}_{4} / \mathrm{C}_{2} \mathrm{H}_{6}$ separation

\begin{tabular}{|c|c|c|c|c|c|c|c|}
\hline MOF & $S_{\text {ads, }}, \mathrm{C}_{2} \mathrm{H}_{4} / \mathrm{C}_{2} \mathrm{H}_{6}$ & $D_{\mathrm{C}_{2} \mathrm{H}_{4}}\left(\mathrm{~cm}^{2} \mathrm{~s}^{-1}\right)$ & $D_{\mathrm{C}_{2} \mathrm{H}_{6}}\left(\mathrm{~cm}^{2} \mathrm{~s}^{-1}\right)$ & $\begin{array}{l}S_{\text {diff, }} \\
\mathrm{C}_{2} \mathrm{H}_{4} / \mathrm{C}_{2} \mathrm{H}_{6}\end{array}$ & $\begin{array}{l}S_{\text {mem }}, \\
\mathrm{C}_{2} \mathrm{H}_{4} / \mathrm{C}_{2} \mathrm{H}_{6}\end{array}$ & $P_{\mathrm{C}_{2} \mathrm{H}_{4}}$ (Barrer) & $P_{\mathrm{C}_{2} \mathrm{H}_{6}}$ (Barrer) \\
\hline XENZUN & 0.74 & $7.62 \times 10^{-7}$ & $3.94 \times 10^{-7}$ & 1.93 & 1.43 & $6.47 \times 10^{2}$ & $4.53 \times 10^{2}$ \\
\hline TUDJOS & 0.62 & $2.22 \times 10^{-5}$ & $1.10 \times 10^{-5}$ & 2.01 & 1.25 & $1.59 \times 10^{4}$ & $1.28 \times 10^{4}$ \\
\hline YARYEV & 0.70 & $2.19 \times 10^{-5}$ & $1.26 \times 10^{-5}$ & 1.74 & 1.21 & $1.17 \times 10^{4}$ & $9.65 \times 10^{3}$ \\
\hline KEXFAU & 0.80 & $2.15 \times 10^{-5}$ & $1.46 \times 10^{-5}$ & 1.47 & 1.17 & $1.12 \times 10^{4}$ & $9.60 \times 10^{3}$ \\
\hline
\end{tabular}


Table 4 Top ten MOF membranes for $\mathrm{C}_{2} \mathrm{H}_{6} / \mathrm{CH}_{4}$ separation

\begin{tabular}{|c|c|c|c|c|c|c|c|}
\hline MOF & $S_{\mathrm{ads},}, \mathrm{C}_{2} \mathrm{H}_{6} / \mathrm{CH}_{4}$ & $D_{\mathrm{C}_{2} \mathrm{H}_{6}}\left(\mathrm{~cm}^{2} \mathrm{~s}^{-1}\right)$ & $D_{\mathrm{CH}_{4}}\left(\mathrm{~cm}^{2} \mathrm{~s}^{-1}\right)$ & $\begin{array}{l}S_{\text {diff, }} \\
\mathrm{C}_{2} \mathrm{H}_{6} / \mathrm{CH}_{4}\end{array}$ & $\begin{array}{l}S_{\mathrm{mem}}, \\
\mathrm{C}_{2} \mathrm{H}_{6} / \mathrm{CH}_{4}\end{array}$ & $P_{\mathrm{C}_{2} \mathrm{H}_{6}}$ (Barrer) & $P_{\mathrm{CH}_{4}}$ (Barrer) \\
\hline NEXXIZ & 16.49 & $1.41 \times 10^{-4}$ & $1.14 \times 10^{-4}$ & 1.24 & 20.46 & $2.12 \times 10^{5}$ & $1.04 \times 10^{4}$ \\
\hline TIRQOB & 13.07 & $1.81 \times 10^{-6}$ & $1.70 \times 10^{-6}$ & 1.07 & 13.98 & $2.72 \times 10^{3}$ & $1.95 \times 10^{2}$ \\
\hline CAYDOX & 14.01 & $1.10 \times 10^{-4}$ & $1.11 \times 10^{-4}$ & 0.99 & 13.88 & $5.20 \times 10^{4}$ & $3.74 \times 10^{3}$ \\
\hline ZUQPOQ & 10.10 & $3.71 \times 10^{-6}$ & $2.72 \times 10^{-6}$ & 1.37 & 13.81 & $2.18 \times 10^{3}$ & $1.58 \times 10^{2}$ \\
\hline LUMDIG & 24.77 & $2.01 \times 10^{-5}$ & $4.12 \times 10^{-5}$ & 0.49 & 12.08 & $2.81 \times 10^{4}$ & $2.33 \times 10^{3}$ \\
\hline SUTBIT & 12.32 & $2.13 \times 10^{-4}$ & $2.17 \times 10^{-4}$ & 0.98 & 12.07 & $6.31 \times 10^{5}$ & $5.23 \times 10^{4}$ \\
\hline CAYGIU & 13.09 & $1.12 \times 10^{-4}$ & $1.23 \times 10^{-4}$ & 0.91 & 11.86 & $5.31 \times 10^{4}$ & $4.48 \times 10^{3}$ \\
\hline
\end{tabular}
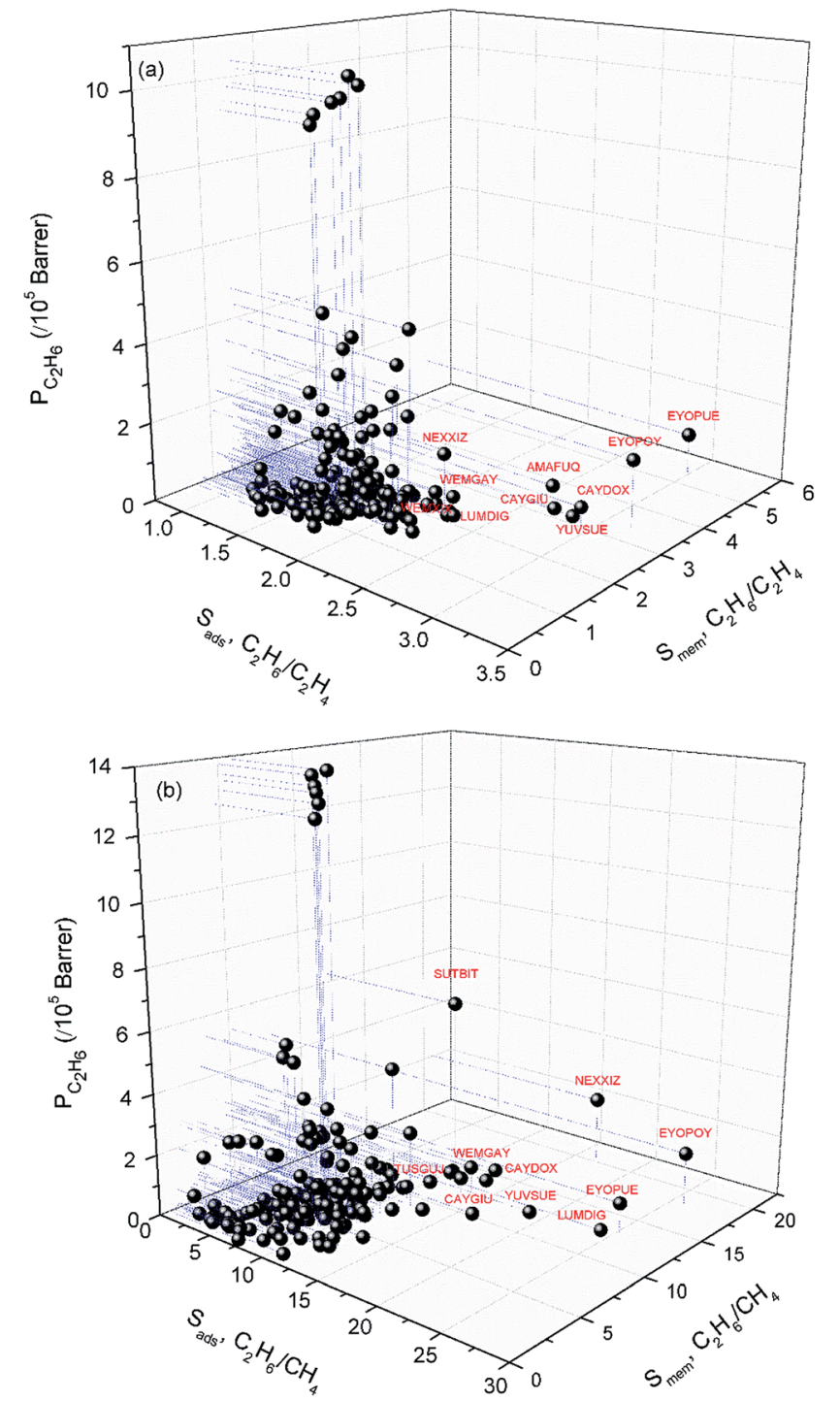

Fig. 3 Adsorption selectivity, membrane selectivity and $\mathrm{C}_{2} \mathrm{H}_{6}$ permeability of MOFs for (a) $\mathrm{C}_{2} \mathrm{H}_{6} / \mathrm{C}_{2} \mathrm{H}_{4}$ and (b) $\mathrm{C}_{2} \mathrm{H}_{6} / \mathrm{CH}_{4}$ separations. Top ten MOFs for (a) $\mathrm{C}_{2} \mathrm{H}_{6} / \mathrm{C}_{2} \mathrm{H}_{4}$ and (b) $\mathrm{C}_{2} \mathrm{H}_{6} / \mathrm{CH}_{4}$ separations are labelled with red labels. Blue dashed lines are to guide the eye. adsorption and membrane selectivities of MOFs were computed to be 1.1-3.2 and 0.7-5.4, respectively and $\mathrm{C}_{2} \mathrm{H}_{6}$ permeabilities of MOFs were predicted to be 41-1.04 $\times 10^{6}$ Barrer. For $\mathrm{C}_{2} \mathrm{H}_{6}$ / $\mathrm{CH}_{4}$ separation, adsorption and membrane selectivities were calculated to be 1.9-26.2 and 0.60-20.5, respectively with $\mathrm{C}_{2} \mathrm{H}_{6}$
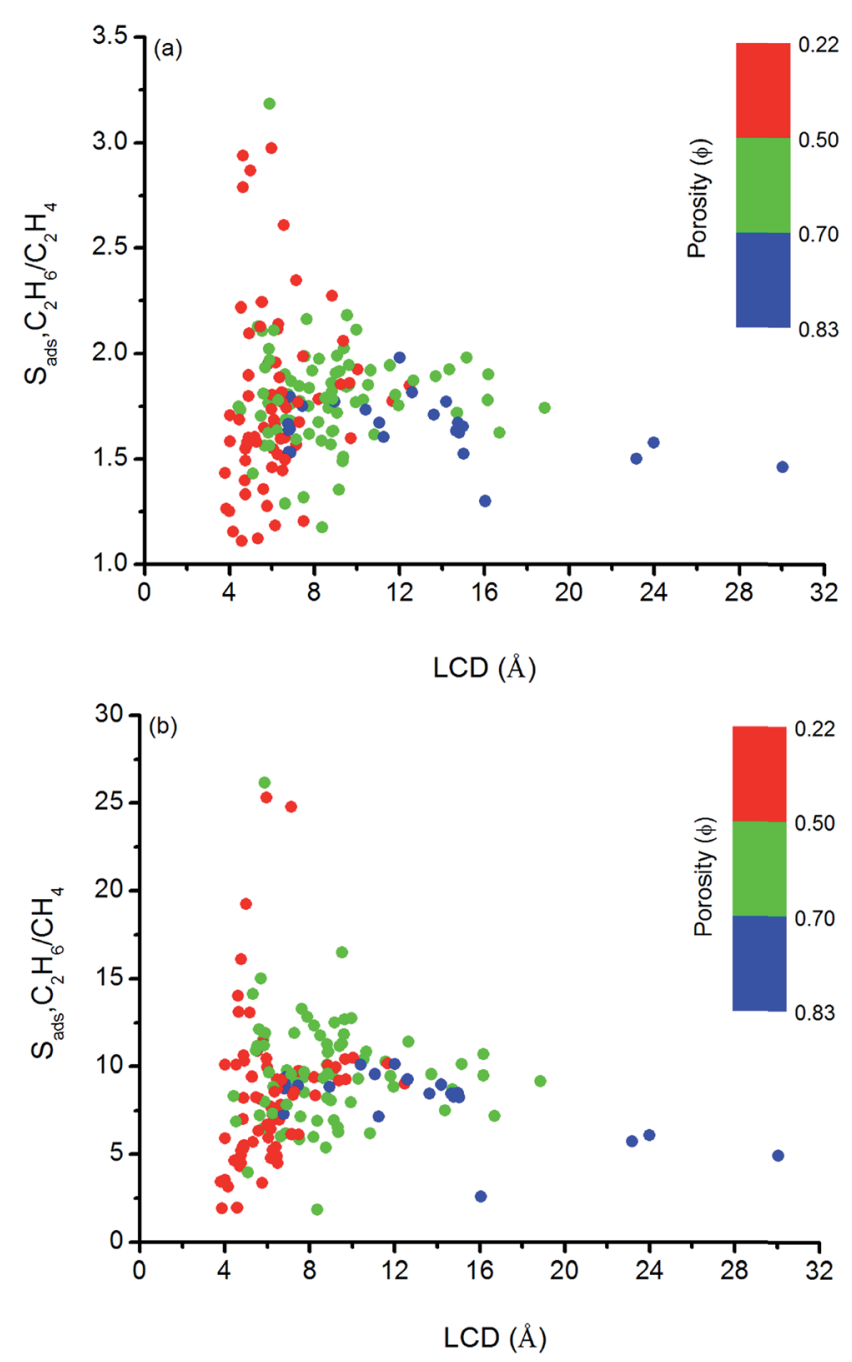

Fig. 4 Relation between adsorption selectivities and LCDs of MOFs as a function of porosities for (a) $\mathrm{C}_{2} \mathrm{H}_{6} / \mathrm{C}_{2} \mathrm{H}_{4}$ and (b) $\mathrm{C}_{2} \mathrm{H}_{6} / \mathrm{CH}_{4}$ separations. 

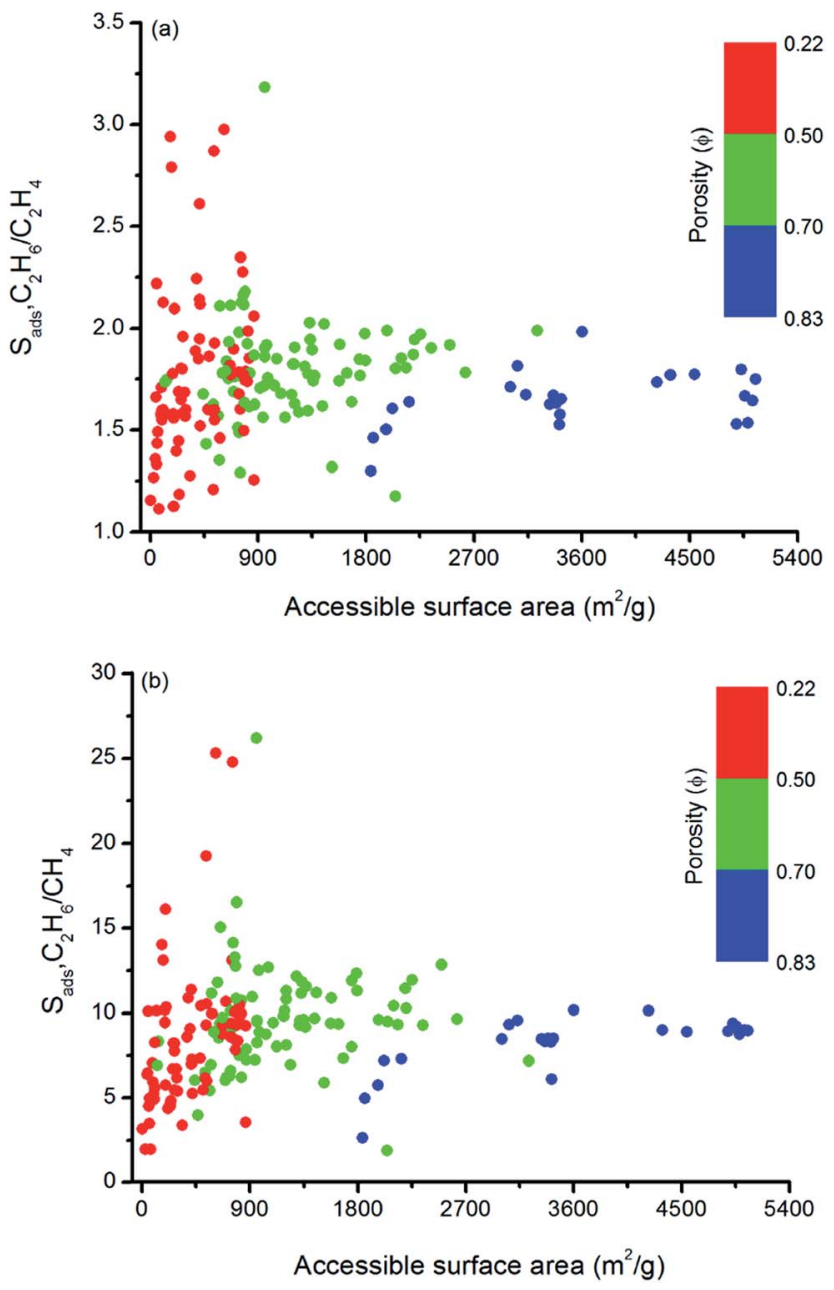

Fig. 5 Relation between adsorption selectivities and surface areas of MOFs as a function of porosities for (a) $\mathrm{C}_{2} \mathrm{H}_{6} / \mathrm{C}_{2} \mathrm{H}_{4}$ and (b) $\mathrm{C}_{2} \mathrm{H}_{6} / \mathrm{CH}_{4}$ separations.

permeabilities of $49.5-1.39 \times 10^{6}$ Barrer. We set the minimum adsorption and membrane selectivity to 2 and showed the top ten MOFs with the highest $\mathrm{C}_{2} \mathrm{H}_{6}$ permeabilities for $\mathrm{C}_{2} \mathrm{H}_{6} / \mathrm{C}_{2} \mathrm{H}_{4}$ separation in Fig. 3(a). Similarly, for $\mathrm{C}_{2} \mathrm{H}_{6} / \mathrm{CH}_{4}$ separation, we considered the MOFs that have adsorption and membrane selectivities larger than 10. After these two constraints we identified the MOFs with the highest $\mathrm{C}_{2} \mathrm{H}_{6}$ permeabilities in Fig. 3(b). Results show that MOFs named as EYOPOY, NEXXIZ, EYOPUE, CAYDOX, WEMGAY, CAYGIU, LUMDIG and YUVSUE are common in the top ten promising material list of $\mathrm{C}_{2} \mathrm{H}_{6} / \mathrm{C}_{2} \mathrm{H}_{4}$ and $\mathrm{C}_{2} \mathrm{H}_{6} / \mathrm{CH}_{4}$ separations. For example, EYOPOY has high adsorption-based selectivity both for $\mathrm{C}_{2} \mathrm{H}_{6} / \mathrm{C}_{2} \mathrm{H}_{4}(3.2)$ and $\mathrm{C}_{2} \mathrm{H}_{6}$ / $\mathrm{CH}_{4}$ (26.2) in addition to high membrane-based selectivity both for $\mathrm{C}_{2} \mathrm{H}_{6} / \mathrm{C}_{2} \mathrm{H}_{4}$ (3.4) and $\mathrm{C}_{2} \mathrm{H}_{6} / \mathrm{CH}_{4}$ (18). This result suggests that these 8 MOFs can be used as effective adsorbents and membranes for the selective separation of $\mathrm{C}_{2} \mathrm{H}_{6}$ from $\mathrm{C}_{2} \mathrm{H}_{4}$ and $\mathrm{CH}_{4}$.

\subsection{Structure-performance relations for MOFs}

We so far focused on the gas separation performance of MOFs as adsorbents and as membranes. Establishing relation

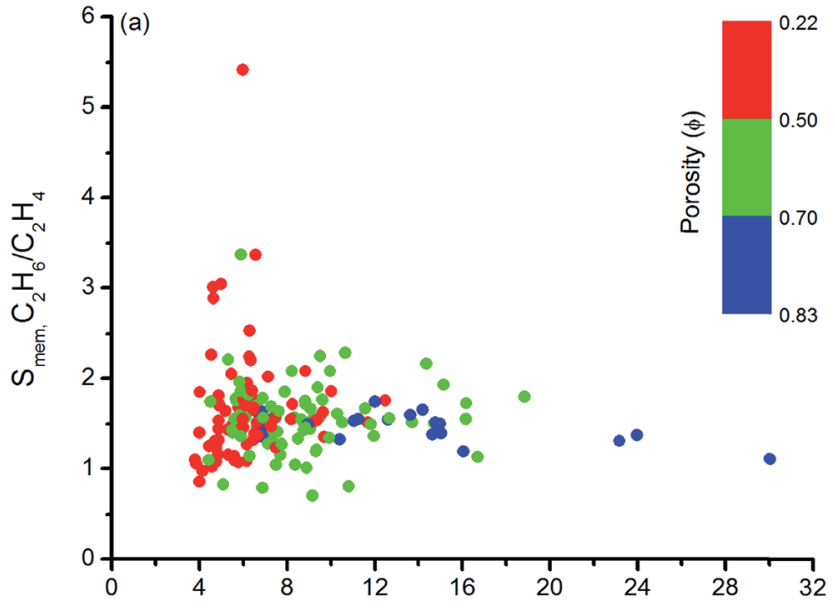

$\operatorname{LCD}(\AA)$

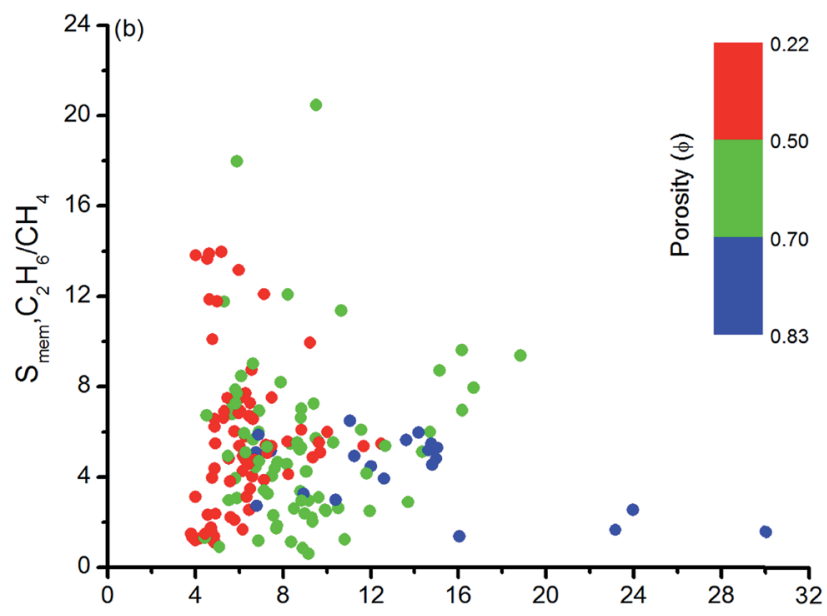

$\operatorname{LCD}(\AA)$

Fig. 6 Relation between membrane selectivities and LCDs of MOFs as a function of porosities for (a) $\mathrm{C}_{2} \mathrm{H}_{6} / \mathrm{C}_{2} \mathrm{H}_{4}$ and (b) $\mathrm{C}_{2} \mathrm{H}_{6} / \mathrm{CH}_{4}$ separations.

between structures and separation performances of MOFs would be very useful to save computational time and to guide the experimental studies for the synthesis of materials with the desired topology. However, clear identification of this type of relations is challenging because separation performance of a material is determined by the interplay of various factors such as chemical topology, porosity, pore size and shape and it cannot be simply correlated to only a single or two structural properties. ${ }^{82}$ In order to simply structure-performance analysis, we examined the relation between selectivity and easily computable structural properties of MOFs such as pore size, porosity, and surface area. Fig. 4 shows that there is a correlation between adsorption selectivity and LCD as well as porosity of MOFs. MOFs with LCDs around 4.5-6 ̊ generally exhibit higher $\mathrm{C}_{2} \mathrm{H}_{6} / \mathrm{C}_{2} \mathrm{H}_{4}$ and $\mathrm{C}_{2} \mathrm{H}_{6} / \mathrm{CH}_{4}$ selectivities $(>2$ and $>10$, respectively) than MOFs with larger pore sizes. As the LCD increases, selectivity generally decreases. MOFs that have large LCDs ( $>6 \AA$ ) have lower $\mathrm{C}_{2} \mathrm{H}_{6} / \mathrm{C}_{2} \mathrm{H}_{4}$ and $\mathrm{C}_{2} \mathrm{H}_{6} / \mathrm{CH}_{4}$ selectivities 

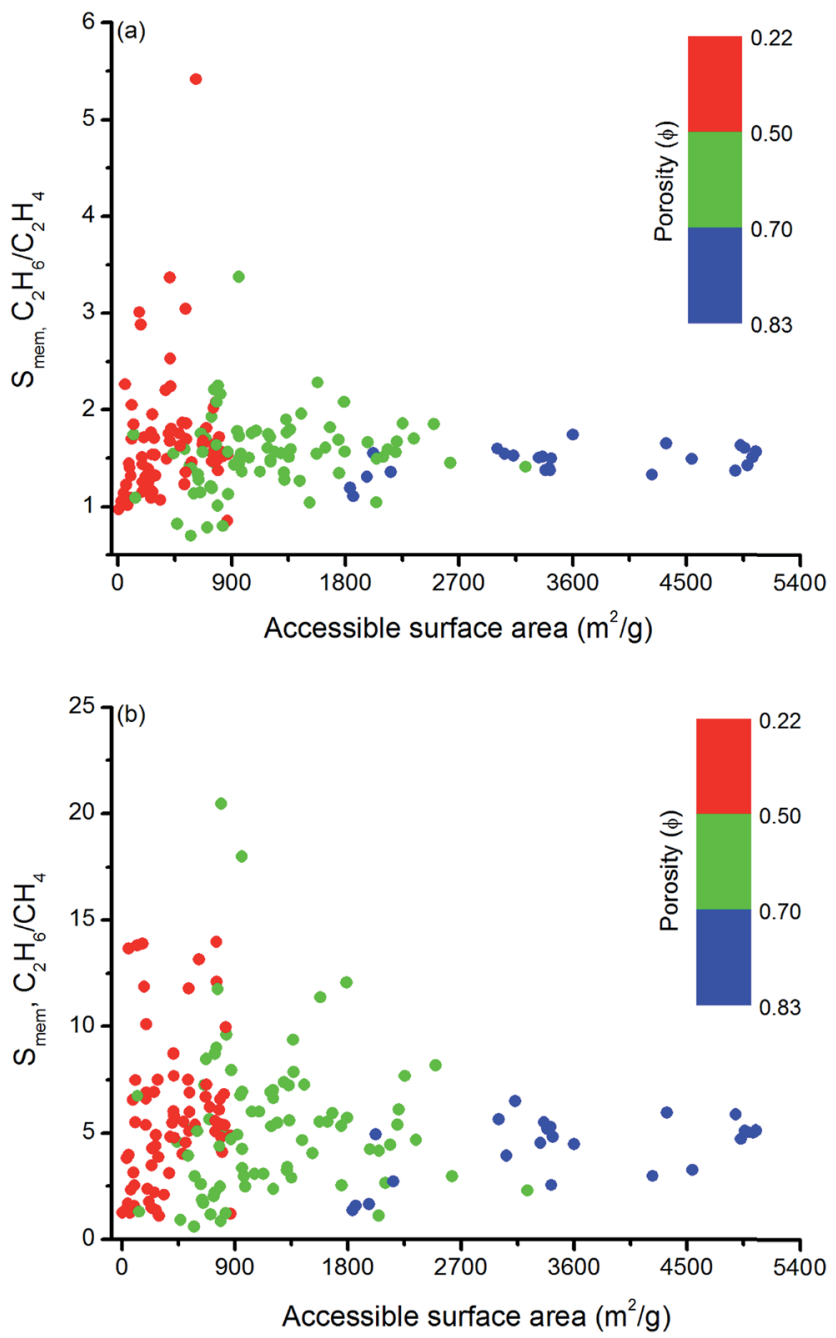

Fig. 7 Relation between membrane selectivities and accessible surface areas of MOFs as a function of porosities for (a) $\mathrm{C}_{2} \mathrm{H}_{6} / \mathrm{C}_{2} \mathrm{H}_{4}$ and (b) $\mathrm{C}_{2} \mathrm{H}_{6} / \mathrm{CH}_{4}$ separation.

( $<2$ and $<10$, respectively) since both gas molecules can easily pass through the pores. Fig. 4 also shows that increasing porosity decreases the adsorption selectivity and this is the common outcome for both gas separations. The porosity of MOFs we considered in this work ranges from 0.22 to 0.83 . Although the color labeling is not distinct in Fig. 4, it is clear that MOFs with porosity lower than 0.50 exhibit higher selectivity.

Similarly, Fig. 5 shows that MOFs having lower surface areas exhibit higher adsorption selectivity. For example, MOFs with surface areas in the range of $500-1000 \mathrm{~m}^{2} \mathrm{~g}^{-1}$ and $750-1000 \mathrm{~m}^{2} \mathrm{~g}^{-1}$ tend to show adsorption selectivities higher than 2 and 10 for $\mathrm{C}_{2} \mathrm{H}_{6} / \mathrm{C}_{2} \mathrm{H}_{4}$ and $\mathrm{C}_{2} \mathrm{H}_{6} / \mathrm{CH}_{4}$ separations, respectively. Overall, results of our structure-performance analysis suggest that MOFs with LCDs around $4.5-6 \AA$, porosities less than 0.50 , and surface areas in the range of $500-1000 \mathrm{~m}^{2} \mathrm{~g}^{-1}$ can be potentially promising adsorbents for efficient $\mathrm{C}_{2} \mathrm{H}_{6}$ separations.

Similar structure-performance analysis was carried out to unlock the relation between membrane selectivity of MOFs,
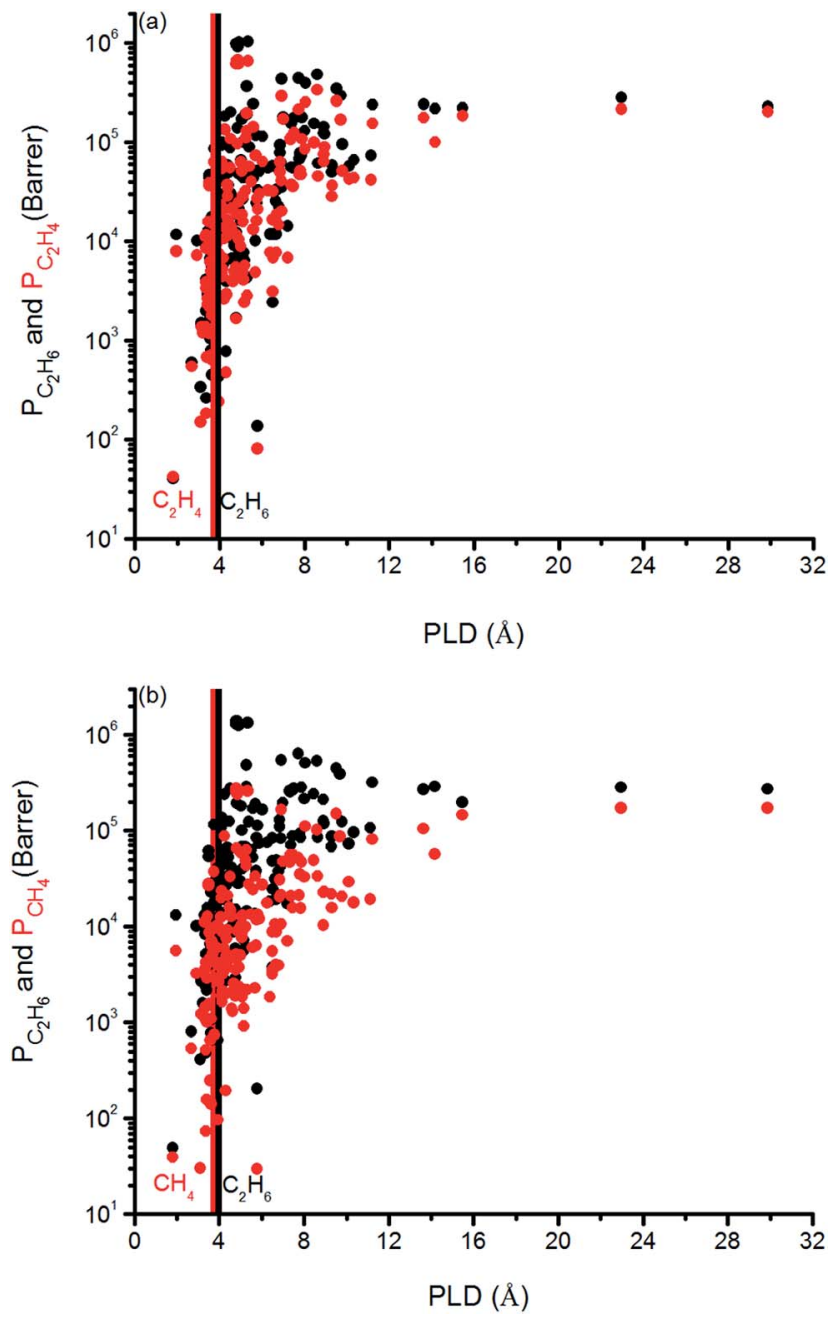

Fig. 8 Relation between gas permeabilities and PLDs of MOFs for (a) $\mathrm{C}_{2} \mathrm{H}_{6} / \mathrm{C}_{2} \mathrm{H}_{4}$ and (b) $\mathrm{C}_{2} \mathrm{H}_{6} / \mathrm{CH}_{4}$ separations. Black symbols represent the $\mathrm{C}_{2} \mathrm{H}_{6}$ permeabilities, red symbols represent permeabilities of $\mathrm{C}_{2} \mathrm{H}_{4}$ in (a) and $\mathrm{CH}_{4}$ in (b).

pore sizes, porosities and surface areas. Fig. 6 shows that membranes with LCDs in the range of 6-7 $\AA$ and 6-9 $\AA$ are more selective for separation of $\mathrm{C}_{2} \mathrm{H}_{6}$ from $\mathrm{C}_{2} \mathrm{H}_{4}$ and $\mathrm{CH}_{4}$, respectively. It is also observed that among the two MOFs with close LCDs but different porosities, the MOF with lower porosity generally have higher membrane selectivity. For example, EYOPUE and SUBDOI have close LCDs (5.97 $\AA$ and $6.29 \AA$ ) but different porosities ( 0.46 and 0.56 ). The one with the lower porosity exhibits high membrane selectivity (5.41) whereas the other one has low membrane selectivity (1.14). This example underlines the importance of the material's porosity on the membrane selectivity. Similar to the adsorption selectivity, as the surface area and porosity decrease, membrane selectivity increases as shown in Fig. 7. For $\mathrm{C}_{2} \mathrm{H}_{6} / \mathrm{C}_{2} \mathrm{H}_{4}$ and $\mathrm{C}_{2} \mathrm{H}_{6} / \mathrm{CH}_{4}$ separation, we obtained the highest membrane selectivities (5.4 and 20.5, respectively) when the surface areas of the MOFs are between $500-1000 \mathrm{~m}^{2} \mathrm{~g}^{-1}$ and $750-1000 \mathrm{~m}^{2} \mathrm{~g}^{-1}$, respectively.

We finally investigated the effect of pore size on the gas permeabilities of MOFs in Fig. 8. Vertical solid lines in this 
figure represent the kinetic diameter of the gas molecules present in the mixture. We specifically focused on the PLD, the smallest pore diameter in the structure, rather than LCD since we refined our MOF database to have the LCDs greater than the kinetic diameters of the gas molecules as we discussed before. It can be seen that once the PLD is slightly larger than the kinetic diameter of a gas molecule, permeability of that gas increases. In Fig. 8(a), $\mathrm{C}_{2} \mathrm{H}_{6}\left(\mathrm{C}_{2} \mathrm{H}_{4}\right)$ permeability increases from $10^{5}$ to $10^{6}$ $\left(10^{4}\right.$ to $\left.10^{5}\right)$ Barrer when PLD is larger than 3.76 (3.68) $\AA$, which is the kinetic diameter of $\mathrm{C}_{2} \mathrm{H}_{6}\left(\mathrm{C}_{2} \mathrm{H}_{4}\right)$ molecule. In Fig. 8(b), $\mathrm{C}_{2} \mathrm{H}_{6}$ and $\mathrm{CH}_{4}$ permeabilities increase from $10^{5}$ to $10^{6}$ Barrer and from $10^{4}$ to $10^{5}$ Barrer for the MOFs that have PLD values slightly larger than $3.76 \AA$ and $3.73 \AA$, the kinetic diameters of $\mathrm{C}_{2} \mathrm{H}_{6}$ and $\mathrm{CH}_{4}$, respectively. These increases can be attributed to the easier diffusion of gas molecules in the larger pores of MOFs. These results suggest that it is reasonable to choose MOFs with PLD values slightly larger than the kinetic diameters of the gas molecules that are desired to be separated in order to obtain high gas permeabilities.

\section{Conclusions}

In this study, we used GCMC and EMD simulations to compute adsorption and diffusion data of $\mathrm{C}_{2} \mathrm{H}_{6} / \mathrm{C}_{2} \mathrm{H}_{4}$ and $\mathrm{C}_{2} \mathrm{H}_{6} / \mathrm{CH}_{4}$ mixtures in 175 different MOFs. Using this data, membrane performances of MOFs were assessed for these two important gas separations. Majority of the MOFs we considered was identified as $\mathrm{C}_{2} \mathrm{H}_{6}$ selective membranes and a small number of MOFs was identified as $\mathrm{C}_{2} \mathrm{H}_{4}$ selective. This result is important since membranes that are selective for $\mathrm{C}_{2} \mathrm{H}_{6}$ over $\mathrm{C}_{2} \mathrm{H}_{4}$ are scarce in the literature and almost all traditional membrane materials such as polymers, zeolites and CMSs are $\mathrm{C}_{2} \mathrm{H}_{4}$ selective. MOF membranes that we considered in this work were found to exhibit higher gas permeabilities than these well-known membrane materials due to their highly porous structures. Examining the structure-performance relations of MOF membranes revealed that MOFs with porosities lower than 0.50, LCD values between 6-9 $\AA$, and surface areas between 500-1000 $\mathrm{m}^{2} \mathrm{~g}^{-1}$ have the highest selectivities for $\mathrm{C}_{2} \mathrm{H}_{6} / \mathrm{C}_{2} \mathrm{H}_{4}$ and $\mathrm{C}_{2} \mathrm{H}_{6} / \mathrm{CH}_{4}$ separations.

The idea of our work was to identify promising MOF membranes for $\mathrm{C}_{2} \mathrm{H}_{6}$ separations using molecular simulations in order to direct experimental efforts, time and resources to those promising materials for experimental fabrication and testing of membranes under real operating conditions. It is very important to discuss the assumptions made in computational studies in order to evaluate the potential of new membrane materials in real applications. We assumed perfect MOF crystals in our GCMC and EMD simulations and predicted gas separation performances of MOFs as defect-free membranes. In reality, defects may be formed during membrane fabrication and they may reduce the membrane's expected selectivity. The idea of our calculations is that once the potential value of a membrane material has been demonstrated by molecular simulations, further experimental studies can be used to increase the precision of initial assessment. Our molecular simulations do not provide any information about the stability of MOFs, which is very important for real applications. An efficient membrane material must keep its structural stability under industrial operation conditions. This issue is more likely to be addressed experimentally. We searched for the stability information of the two MOFs, EYOPUE and NEXXIZ, which were identified as the top promising membrane material for selective separation of $\mathrm{C}_{2} \mathrm{H}_{6}$ from $\mathrm{C}_{2} \mathrm{H}_{4}$ and $\mathrm{CH}_{4}$, respectively. Experiments reported that they can retain their crystalline integrity at ambient conditions. ${ }^{83,84}$ The value of our computational work is that it can provide a motivation to perform detailed experimental studies for the thermal and structural stability of promising membrane materials. We believe that results of this work will guide experimental studies for the design and synthesis of new MOFs with better separation performances for $\mathrm{C}_{2} \mathrm{H}_{6}$ separations.

\section{Conflicts of interest}

There are no conflicts to declare.

\section{Acknowledgements}

S. K. acknowledges ERC-2017-Starting Grant. This study has received funding from the European Research Council (ERC) under the European Union's Horizon 2020 research and innovation programme (ERC-2017-Starting Grant, grant agreement No 756489-COSMOS).

\section{References}

1 D. Banerjee, J. Liu and P. K. Thallapally, Comments Inorg. Chem., 2015, 35, 18-38.

2 M. Shi, C. C. H. Lin, T. M. Kuznicki, Z. Hashisho and S. M. Kuznicki, Chem. Eng. Sci., 2010, 65, 3494-3498.

3 F. X. Coudert and A. H. Fuchs, Coord. Chem. Rev., 2016, 307, 211-236.

4 M. Eddaoudi, H. Li and O. M. Yaghi, J. Am. Chem. Soc., 2000, 122, 1391-1397.

5 R. B. Getman, Y. S. Bae, C. E. Wilmer and R. Q. Snurr, Chem. Rev., 2012, 112, 703-723.

6 S. Keskin, in Molecular Dynamics-Theoretical Developments and Applications in Nanotechnology and Energy, ed. L. Wang, InTech, 2012.

7 S. Xiang, Y. He, Z. Zhang, H. Wu, W. Zhou, R. Krishna and B. Chen, Nat. Commun., 2012, 3, 954-962.

8 A. Battisti, S. Taioli and G. Garberoglio, Microporous Mesoporous Mater., 2011, 143, 46-53.

9 R. Babarao and J. Jiang, Langmuir, 2008, 24, 5474-5484.

10 Y. Liu, D. Liu, Q. Yang, C. Zhong and J. Mi, Ind. Eng. Chem. Res., 2010, 49, 2902-2906.

11 R. Krishna, RSC Adv., 2015, 5, 52269-52295.

12 J. McEwen, J. D. Hayman and A. O. Yazaydin, Chem. Phys., 2013, 412, 72-76.

13 Z. B. Bao, S. Alnemrat, L. Yu, I. Vasiliev, Q. L. Ren, X. Y. Lu and S. G. Deng, Langmuir, 2011, 27, 13554-13562. 
14 U. Böhme, B. Barth, C. Paula, A. Kuhnt, W. Schwieger, A. Mundstock, J. Caro and M. Hartmann, Langmuir, 2013, 29, 8592-8600.

15 H. Bux, C. Chmelik, R. Krishna and J. Caro, J. Membr. Sci., 2011, 369, 284-289.

16 C. Gücüyener, J. van den Bergh, J. Gascon and F. Kapteijn, J. Am. Chem. Soc., 2010, 132, 17704-17706.

17 Y. He, R. Krishna and B. Chen, Energy Environ. Sci., 2012, 5, 9107-9120.

18 Y. He, Z. Zhang, S. Xiang, F. R. Fronczek, R. Krishna and B. Chen, Chem.-Eur. J., 2012, 18, 613-619.

19 C. E. Wilmer, O. K. Farha, T. Yildirim, I. Eryazici, V. Krungleviciute, A. A. Sarjeant, R. Q. Snurr and J. T. Hupp, Energy Environ. Sci., 2013, 6, 1158-1163.

20 Y. Zhang, B. Li, R. Krishna, Z. Wu, D. Ma, Z. Shi, T. Pham, K. Forrest, B. Space and S. Ma, Chem. Commun., 2015, 51, 2714-2717.

21 M. Hartmann, U. Böhme, M. Hovestadt and C. Paula, Langmuir, 2015, 31, 12382-12389.

22 P.-Q. Liao, W.-X. Zhang, J.-P. Zhang and X.-M. Chen, Nat. Commun., 2015, 6, 1-9.

23 E. D. Bloch, W. L. Queen, R. Krishna, J. M. Zadrozny, C. M. Brown and J. R. Long, Science, 2012, 335, 1606-1610.

24 H. C. Guo, F. Shi, Z. F. Ma and X. Q. Liu, Mol. Simul., 2014, 40, 349-360.

25 Y. Wu, H. Y. Chen, D. F. Liu, Y. Qian and H. X. Xi, Chem. Eng. Sci., 2015, 124, 144-153.

26 R. S. Pillai, M. L. Pinto, J. Pires, M. Jorge and J. R. B. Gomes, ACS Appl. Mater. Interfaces, 2015, 7, 624-637.

27 C. Altintas and S. Keskin, Chem. Eng. Sci., 2016, 139, 49-60.

28 S. S. Chan, T.-S. Chung, Y. Liu and R. Wang, J. Membr. Sci., 2003, 218, 235-245.

29 S. S. Chan, R. Wang, T.-S. Chung and Y. Liu, J. Membr. Sci., 2002, 210, 55-64.

30 C. Staudt-Bickel and W. J. Koros, J. Membr. Sci., 2000, 170, 205-214.

31 K. Tanaka, A. Taguchi, J. Hao, H. Kita and K. Okamoto, J. Membr. Sci., 1996, 121, 197-207.

32 Y. Pan and Z. Lai, Chem. Commun., 2011, 47, 10275-10277.

33 A. Huang, N. Wang, C. Kong and J. Caro, Angew. Chem., Int. Ed., 2012, 51, 10551-10555.

34 S. Japip, H. Wang, Y. Xiao and T. Shung Chung, J. Membr. Sci., 2014, 467, 162-174.

35 R. Mueller, V. Hariharan, C. Zhang, R. Lively and S. Vasenkov, J. Membr. Sci., 2016, 499, 12-19.

36 J. Ploegmakers, S. Japip and K. Nijmeijer, J. Membr. Sci., 2013, 428, 445-453.

37 J. E. Bachman, Z. P. Smith, T. Li, T. Xu and J. R. Long, Nat. Mater., 2016, 15, 845-849.

38 F. Stallmach, S. Gröger, V. Künzel, J. Kärger, O. Yaghi, M. Hesse and U. Müller, Angew. Chem., Int. Ed., 2006, 45, 2123-2126.

39 D. C. Ford, D. Dubbeldam, R. Q. Snurr, V. Künzel, M. Wehring, F. Stallmach, J. Kärger and U. Müller, J. Phys. Chem. Lett., 2012, 3, 930-933.

40 C. Chmelik, D. Freude, H. Bux and J. Haase, Microporous Mesoporous Mater., 2012, 147, 135-141.
41 A. I. Skoulidas and D. S. Sholl, J. Phys. Chem. B, 2005, 109, 15760-15768.

42 L. Sarkisov, T. Düren and R. Q. Snurr, Mol. Phys., 2004, 102, 211-221.

43 B. Borah, H. Zhang and R. Q. Snurr, Chem. Eng. Sci., 2015, 124, 135-143.

44 T. Chokbunpiam, R. Chanajaree, O. Saengsawang, S. Reimann, C. Chmelik, S. Fritzsche, J. Caro, T. Remsungnen and S. Hannongbua, Microporous Mesoporous Mater., 2013, 174, 126-134.

45 P. Krokidas, M. Castier, S. Moncho, E. Brothers and I. G. Economou, J. Phys. Chem. C, 2015, 119, 27028-27037.

46 R. J. Verploegh, S. Nair and D. S. Sholl, J. Am. Chem. Soc., 2015, 137, 15760-15771.

47 Y. G. Chung, J. Camp, M. Haranczyk, B. J. Sikora, W. Bury, V. Krungleviciute, T. Yildirim, O. K. Farha, D. S. Sholl and R. Q. Snurr, Chem. Mater., 2014, 26, 6185-6192.

48 K. B. Sezginel, A. Uzun and S. Keskin, Chem. Eng. Sci., 2015, 124, 125-134.

49 M. Fischer, J. R. B. Gomes and M. Jorge, Mol. Simul., 2014, 40, 537-556.

50 F. Allen, Acta Crystallogr., Sect. B: Struct. Sci., 2002, 58, 380388.

51 L. Sarkisov and A. Harrison, Mol. Simul., 2011, 37, 12481257.

52 S. L. Mayo, B. D. Olafson and W. A. Goddard, J. Phys. Chem. C, 1990, 94, 8897-8909.

53 D. Frenkel and B. Smit, Understanding Molecular Simulation: From Algorithms to Applications, Academic Press, San Diego, 2nd edn, 2002.

54 A. K. Rappe, C. J. Casewit, K. S. Colwell, W. A. Goddard and W. M. Skiff, J. Am. Chem. Soc., 1992, 114, 10024-10035.

55 M. G. Martin and J. I. Siepmann, J. Phys. Chem. B, 1998, 102, 2569-2577.

56 S. Keskin and D. S. Sholl, Langmuir, 2009, 25, 11786-11795.

57 I. Erucar and S. Keskin, Ind. Eng. Chem. Res., 2013, 52, 34623472.

58 J. Perez-Pellitero, H. Amrouche, F. R. Siperstein, G. Pirngruber, C. Nieto-Draghi, G. Chaplais, A. SimonMasseron, D. Bazer-Bachi, D. Peralta and N. Bats, Chem.Eur. J., 2010, 16, 1560-1571.

59 J. A. Greathouse and M. D. Allendorf, J. Phys. Chem. C, 2008, 112, 5795-5802.

60 E. Haldoupis, T. Watanabe, S. Nair and D. S. Sholl, ChemPhysChem, 2012, 13, 1-4.

61 I. Erucar and S. Keskin, J. Membr. Sci., 2016, 514, 313-321.

62 M. Witman, S. Ling, S. Jawahery, P. G. Boyd, M. Haranczyk, B. Slater and B. Smit, J. Am. Chem. Soc., 2017, 139, 55475557.

63 R. Krishna and D. Paschek, Phys. Chem. Chem. Phys., 2002, 4, 1891-1898.

64 Y. Basdogan, K. B. Sezginel and S. Keskin, Ind. Eng. Chem. Res., 2015, 54, 8479-8491.

65 E. Adatoz and S. Keskin, J. Nanomater., 2015, 2015, 1-9.

66 G. Garberoglio and R. Vallauri, Microporous Mesoporous Mater., 2008, 116, 540-547. 
67 M. Rungta, C. Zhang, W. J. Koros and L. R. Xu, AIChE J., 2013, 59, 3475-3489.

68 L. M. Robeson, J. Membr. Sci., 2008, 320, 390-400.

69 T. A. Centeno and A. B. Fuertes, J. Membr. Sci., 1999, 160, 201-211.

70 A. B. Fuertes and I. Menendez, Sep. Purif. Technol., 2002, 28, 29-41.

71 J.-i. Hayashi, H. Mizuta, M. Yamamoto, K. Kusakabe, S. Morooka and S.-H. Suh, Ind. Eng. Chem. Res., 1996, 35, 4176-4181.

72 C. Zhang, R. P. Lively, K. Zhang, J. R. Johnson, O. Karvan and W. J. Koros, J. Phys. Chem. Lett., 2012, 3, 2130-2134.

73 L. Starannikova, Y. Yampolskii, K. Makovetskii and T. Golenko, Desalination, 2006, 200, 18-19.

74 I. Pinnau and Z. He, J. Membr. Sci., 2004, 244, 227-233.

75 W. Dai, M. Scheibe, L. Li, N. Guan and M. Hunger, J. Phys. Chem. C, 2012, 116, 2469-2476.
76 A. Romero-Pérez and G. Aguilar-Armenta, J. Chem. Eng. Data, 2010, 55, 3625-3630.

77 D. M. Ruthven and S. C. Reyes, Microporous Mesoporous Mater., 2007, 104, 59-66.

78 A. Khosravi and M. Sadeghi, J. Membr. Sci., 2013, 434, 171183.

79 I. Tirouni, M. Sadeghi and M. Pakizeh, Sep. Purif. Technol., 2015, 141, 394-402.

80 A. Alentiev, I. G. Economou, E. Finkelshtein, J. Petrou, V. E. Raptis, M. Sanopoulou, S. Soloviev, N. Ushakov and Y. Yampolskii, Polymer, 2004, 45, 6933-6944.

81 W. Robb, Ann. N. Y. Acad. Sci., 1968, 146, 119-137.

82 T. N. Ozturk and S. Keskin, J. Phys. Chem. C, 2014, 118, 13988-13997.

83 K.-H. Cui, S.-Y. Yao, H.-Q. Li, Y.-T. Li, H.-P. Zhao, C.-J. Jiang and Y.-Q. Tian, CrystEngComm, 2011, 13, 3432-3437.

84 T. K. Kim, J. H. Lee, D. Moon and H. R. Moon, Inorg. Chem., 2013, 52, 589-595. 